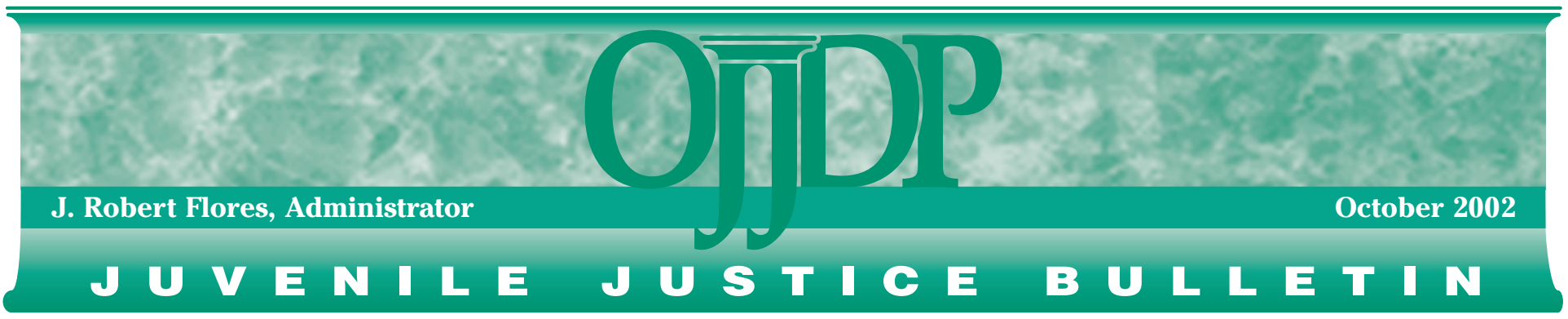

\title{
Trends in Juvenile Violent Offending: An Analysis of Victim Survey Data
}

\begin{abstract}
James P. Lynch
Current understanding of juvenile offending nationally comes primarily from the arrest rates compiled by the Federal Bureau of Investigation (FBI) for its annual Uniform Crime Reports (UCR) (Snyder and Sickmund, 1999; Snyder, 2000). This Bulletin uses data from the National Crime Victimization Survey (NCVS) to estimate offending rates for juveniles from 1980 through 1998 from another perspective.
\end{abstract}

The juvenile offending rates derived from the NCVS data are examined by gender, race, and type of crime. These trends are compared with arrest rate trends based on UCR data. Because victims have little information on crimes in which they do not have face-to-face contact with offenders, this analysis is restricted to violent offending. It is further restricted to relatively serious violent crimes-aggravated assault, robbery, and forcible rape. Simple assaults are excluded because this crime class includes a large number of very minor incidents that are infrequently reported to the police and are arguably very different from the incidents that are likely to be the object of police investigation. Unlike UCR data, NCVS data are not limited to cases that come to the attention of police or result in arrests. Comparing the pictures that emerge from these different data sources can help determine whether the current understanding of juvenile offending reflects more the nature of crime or the peculiarities of the filters through which the problem is viewed.

\section{Trends in Arrest Rates From the FBI's Uniform Crime Reports}

According to UCR data, on average, for the period 1980 to 1998, the juvenile arrest rate for serious violent crimes was 5 per 1,000 persons ages 12 to 17 in the residential population of the United States. ${ }^{1}$ Arrests decreased during the early 1980s and then (with the exception of 1987) increased steadily from 1984 until 1994 (figure 1). They began to decrease in 1995 and continued to decrease through 1998.

Throughout the period 1980 to 1998 , the arrest rates for serious violent crimes were much higher for male juveniles than for female juveniles (figure 2). On average, the arrest rate for male juveniles was 6.6 times that for female juveniles-8.6 per 1,000 and 1.3 per 1,000 , respectively. ${ }^{2}$ The overrepresentation of males in the juvenile arrest rates for serious violent crimes decreased over time. In 1980, the arrest rate for male juveniles was 8.4 times the rate for female juveniles. This imbalance

\section{A Message From OJJDP}

The fact that our assessment of current trends in juvenile offending is based largely on arrest data reported to the Federal Bureau of Investigation (FBI) by local law enforcement agencies raises a fundamental question about the capacity of such data to provide an accurate and comprehensive picture of the myriad challenges that face today's youth and our society.

The information that this Bulletin offers on trends in juvenile violent offending over the past two decades, however, comes from a different source: the victims of those offenses.

Thus, unlike the data derived from the FBI's Uniform Crime Reports, which drive traditional assessments, the information provided by the $\mathrm{Na}$ tional Crime Victimization Surveyand featured in these pages-is not limited to cases that come to the attention of local law enforcement officials, primarily through arrests.

By comparing the pictures of trends in juvenile violent offending that these diverse data sources provide, we can begin to answer the critical question posed above and to determine whether our present understanding of juvenile offending accurately reflects the nature of those crimes-and not merely the nature of its origins.

Accordingly, it is our hope that examining information from a variety of sources about a variety of activities related to juvenile offending will better equip us to prevent and combat such delinquent acts.

\section{Access OJJDP publications online at ojjdp.ncjrs.org}


Figure 1: Juvenile Arrest Rates for Serious Violent Crimes: 1980-98

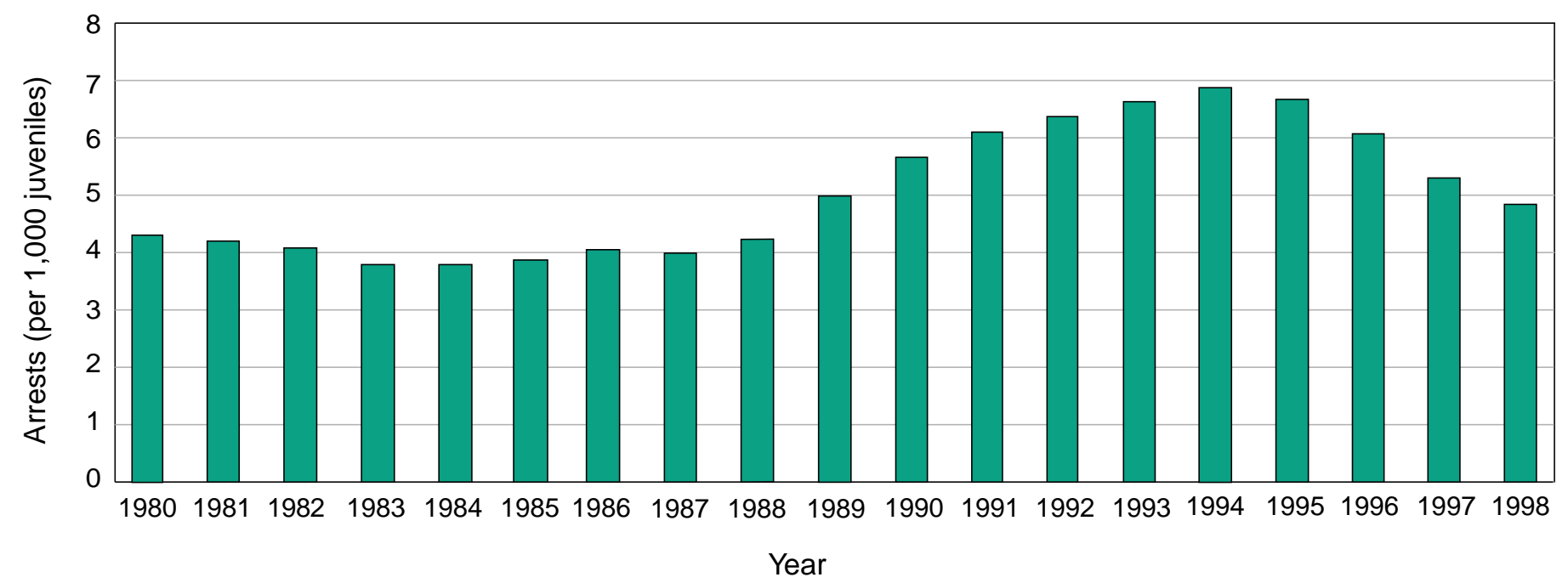

Source: National Center for Juvenile Justice.

Figure 2: Juvenile Arrest Rates for Serious Violent Crimes, by Gender: 1980-98

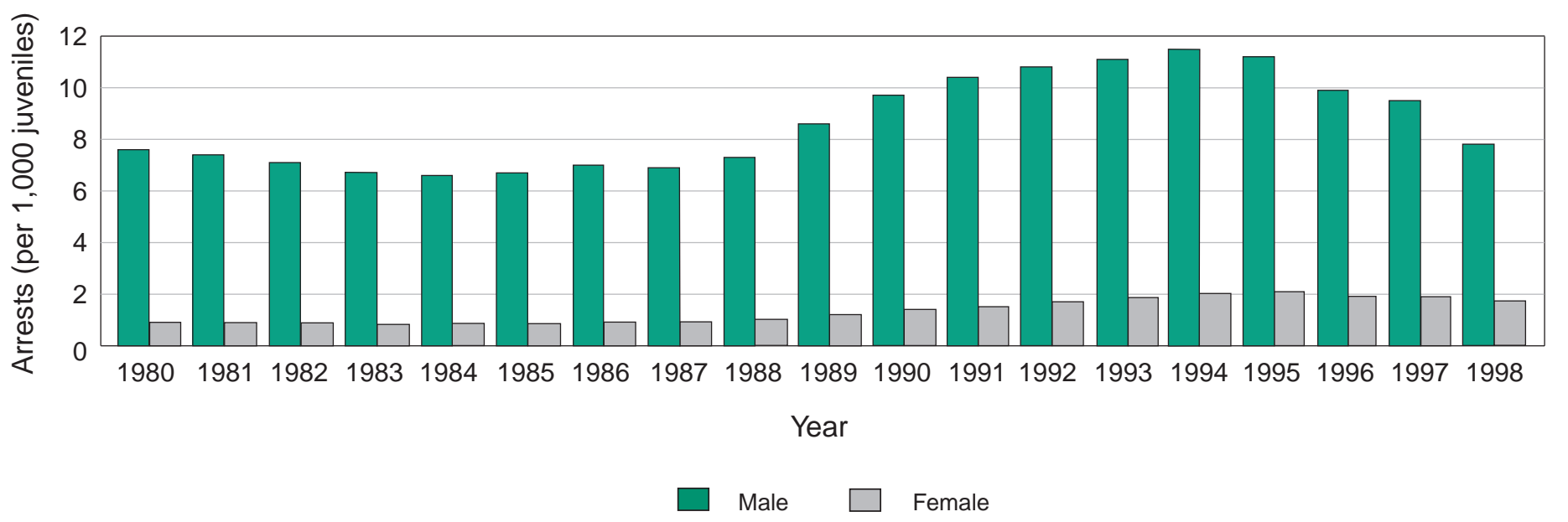

Source: National Center for Juvenile Justice.

declined steadily so that by 1998 the arrest rate for male juveniles was only 4.5 times that for female juveniles.

Throughout the period, the arrest rates for serious violent crimes were much higher for black juveniles than for white juveniles (figure 3)—on average, 16.6 per 1,000 and 3.0 per 1,000 , respectively. The disproportionately larger involvement of black juveniles in arrests for serious violent crimes decreased over time. In 1980, the arrest rate for black juveniles was 6.1 times the rate for white juveniles, and in 1981, the ratio was 6.6. By 1998, it had fallen to 3.9. Although this decrease was pronounced, it was not consistent throughout the period. Much of the decrease occurred between 1996 and 1998.

\section{Limitations of Police- and Offender-Based Data Sources}

One must be cautious in using the foregoing arrest data to make statements about the offender population and the offending rate. UCR arrest data include a highly select group of offenders. Being arrested is 
Figure 3: Juvenile Arrest Rates for Serious Violent Crimes, by Race: 1980-98

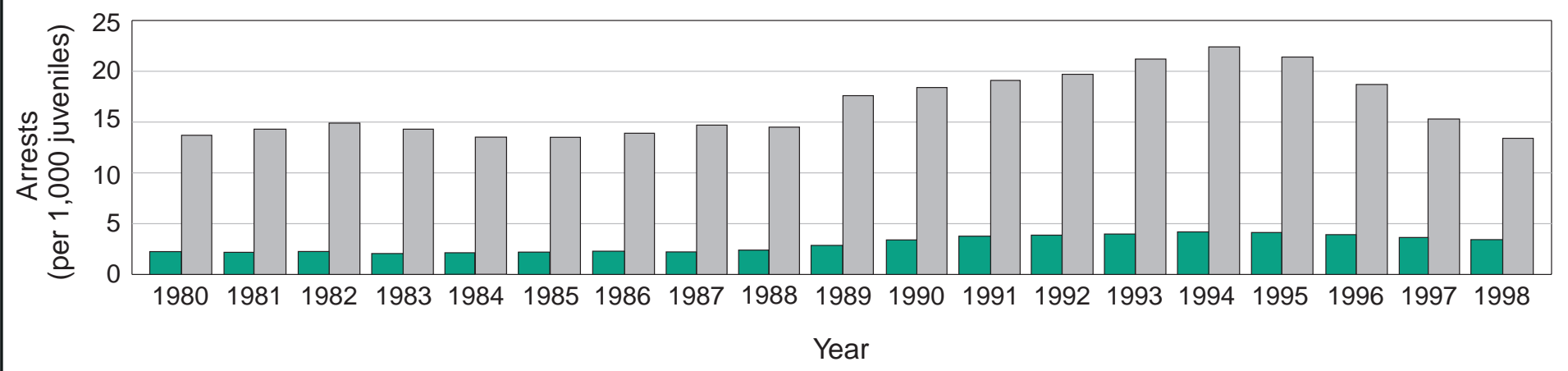

White $\quad \square$ Black

Source: National Center for Juvenile Justice.

imperfectly related to committing an offense. Fewer than 50 percent of all violent crimes are reported to the police (Rennison, 2000). Even when crimes are reported, many offenders are never apprehended (Federal Bureau of Investigation, 1999). Of those individuals identified by the police as offenders, many are not formally charged. Even if police arrested every person who committed a crime, UCR data would still be limited because almost 35 percent of all police departments in the United States fail to completely report their arrest data to the FBI (Jarvis and Lynch, 1996; Maltz, 1999). This nonreporting of arrest data is not uniform across the country. Larger jurisdictions report more completely than smaller jurisdictions. This filtering of cases by the police and policebased data systems can introduce substantial bias in the data.

For these reasons, using arrest rates to approximate offending rates will undoubtedly produce low estimates of offending. To the extent that attributes of offenders (e.g., race, gender) affect the probability of being arrested, UCR arrest data may overrepresent "arrest-prone" groups of offenders. In addition, local police departments' different rates of reporting to the FBI can also distort the picture of the offender population. If large urban police departments that service areas with relatively large black populations, for example, report more completely than smaller suburban departments that service predominately white communities, then black offenders are likely to be overrepresented in UCR arrest data.

The picture of the offender population emerging from self-report surveys of criminal behavior is also somewhat suspect. The samples used in these surveys are relatively small, and there is some concern that, because certain segments of the population-specifically, minority males-are not adequately captured in these household surveys, their representation in the offending population will be understated. Finally, self-report surveys of offending are susceptible to response errors in which respondents strategically overstate or underreport their offending behavior.

For these reasons, the descriptions of the offending population that emerge from these data sources are suspect. Therefore, it is useful to examine the NCVS as another source of information on offenders and offending rates. Although the NCVS has limitations of its own that call the resulting data into question, these limitations are different from those affecting data gathered from police reports and self-report surveys of offending behavior. Consequently, the NCVS can be used in concert with these traditional sources to paint a more complete picture of the offender population. If characteristics of the offender population are similar across the three data sources, then it is more likely that these statistical systems are accurately describing offenders and offending trends. To the extent that the data sources provide varying pictures of juvenile offending, an attempt must be made to understand why.

\section{Trends in Offending Rates From the National Crime Victimization Survey}

The NCVS has existed since 1973 and can, therefore, be used to assess offending rates from that time until 1998 (the year for which the most recent data are available). However, because the methodology employed in the survey changed radically in 1992, the pre-1992 data used in this analysis have been adjusted to make them comparable to the post-1992 data (see “Adjusting NCVS Data” on page 16).

\section{Advantages and Disadvantages of NCVS Data}

The NCVS has some distinct advantages as a source of data on offending behavior, at least for serious violent offenses (Planty, 2000):

- First, the NCVS should capture a greater percentage of offending behavior than can be captured in police records. A large, nonrandom portion of offending behavior is not reported to the police. Some unknown proportion of offending behavior is not reported in victim surveys, but it is certainly less than the proportion not reported to the police.

- Second, the NCVS uses larger samples than the National Longitudinal Survey of Youth (NLSY) and other large-scale selfreport surveys of offending behavior. This larger sample should increase the reliability of the estimates of offending. 


\section{Computing Offending Rates With the NCVS}

The National Crime Victimization Survey (NCVS) is designed to produce victimization rates and incident rates for the residential population of the United States based on a sample from that population:

- Victimization rates estimate the number of people in a given population who have been victims. If two people are robbed at gun point, this would contribute two victimizations to the victimization rate. If four people were robbed, then four victimizations would be added to the victimization rate. The victimization rate is the sum of the estimated number of victimizations divided by the estimate of the population.

- Incident rates indicate the number of crime events that have occurred. The robbery with two victims would contribute only one event to the incident rates because the two people were robbed in the same event. To avoid the possibility of doublecounting an event with two victims, any victimization is divided by the number of victims in the incident, because each victim has the potential to be in the sample and report the event. ${ }^{1}$

Rates can be computed for the entire population or for specific subgroups. ${ }^{2}$

1 The robbery with two victims would be divided by 2 (i.e., one event/two victims) and the result (0.5) would be multiplied by the sample weight to obtain the contribution of this event to an incident count. The results for all incidents would be summed across all respondents to get an incident count for the population. This incident count would be divided by the weighted population count, as in the case of victimization rates, to obtain an incident rate for the population.

2 A subgroup's estimated number of victimizations is developed by multiplying the subgroup's reported number of victimizations by the subgroup's sample weight. The subgroup's population is determined by multiplying the number of respondents in the subgroup by the subgroup's sample weight. The subgroup's sample weight is the inverse of the probability of being selected into the sample. If 10 people are sampled from a subgroup of 100 , the probability of selecting a given person from that subgroup is 1 over 10 or 10 percent. The inverse of the probability (i.e., 1/0.1) is equal to 10 . To produce subgroup population estimates from their sample counts, the counts from the sample would be multiplied by the inverse of the probability of selection, or 10 .

\section{Weighting Incident Rates To Produce Offending Counts}

Generating an offending rate requires an estimate of the number of offending events (that is, crimes committed), which is divided by the population being studied. A given crime incident can have as many offending acts as there are offenders involved. An incident involving three offenders, then, would contribute three offending acts to the offending rate because three different people committed the criminal act. A crime perpetrated by only one person would contribute one offense to the offending rate. ${ }^{3}$ The number of offending acts is computed by multiplying the incident weight by the number of offenders present during the criminal event.

\section{Complications in Computing Offending Rates With the NCVS}

Calculating the offending rate with the NCVS is complicated by nonresponses resulting in missing data, by the way in which the survey asks about crimes involving co-offending, and by the "series incident" procedure used to accommodate high-volume repeat victimization. It is important, therefore, to describe how these problems were taken into account in the computation of the offending rate.

\section{Missing Data}

Nonresponse or missing data are a problem in any data set. Missing data are infrequent in the NCVS, compared with most other data collections (e.g., the UCR or National Woman's Study). The NCVS has a 95-percent response rate and very low item nonresponse. In the case of information on offenders in violent crime incidents, the amount of missing data is small.

3 For a very small proportion of serious violent incidents, the number of offenders reported by the respondent is implausibly large. For the years 1993 to 1998 , for example, victims reported between 1 and 96 offenders present during an incident. Moreover, approximately 1 percent of the serious violent incidents involved more than 10 offenders. Given the fact that these rare events can contribute a great deal to the offending rate and that a respondent cannot accurately count offenders beyond a certain number, the computations of offending rates presented in this Bulletin counted all events with 10 or more offenders as having 10 offenders.
Victims could not report the age of the offenders in only 2 percent of the incidents of violence reported in 1998. Nonresponse for gender and race of the offender was only 0.2 percent and 0.9 percent, respectively. Because so few data are missing (and because several attempts to impute these data proved unsuccessful), cases with missing information on age, race, or gender were excluded from this analysis. This will lead to a slight underestimate of the offending rate.

\section{Co-Offending}

The problem of mixed age, race, and gender groups of offenders is more serious than the missing data problem because a much larger proportion of crimes involve co-offending than missing data. From an information point of view, it would be best to ask the respondent about each offender, but this is burdensome for the respondent and could increase nonresponse in the survey. The NCVS attempts to balance the requirements of maintaining the quality of information and limiting the burden placed on respondents by asking about groups of offenders collectively. So, the survey includes questions about whether all of the assailants were of the same race or gender and what that race or gender was. The problem with reporting on aggregates of offenders is that there will be mixed groups that cannot be allocated to a given race, gender, or age group. If the group includes two men and two women, all that can be known from the NCVS data is that the group contained both men and women.

Age. Because juvenile offending is the focus of this study, it is important to accurately characterize offenders by age. Moreover, the amount of adult and juvenile co-offending is substantial. For these reasons, mixed-age groups could not simply be omitted from the analysis. Instead, this Bulletin provides two estimates of juvenile offending. Offending rates that included adult co-offending assumed that all offenders in mixed-age groups of offenders were juveniles. Offending rates that excluded adult cooffending assumed that all offenders in mixed-age groups of offenders were adults. The first of these estimates will 
be too high and the other will be too low, with a reasonable estimate of the juvenile offending rate being somewhere between the two. In this sense, the two estimates (including and excluding adult co-offending) provide an interval within which the actual juvenile offending rate most likely falls.

Gender and race. A different approach was taken to estimating gender- and race-specific rates of juvenile offending. Here, mixed-gender and mixed-race groups that had a majority of one race or one gender were treated as if all members of the group were of that race or gender. So, if the group included one male and three females, all offenders were counted as female. When the respondent reported that no race or gender group was in the majority, the case was omitted from the estimates. Approximately 7 percent of the violent incidents fell into this category. Here again, this estimation method will contribute to underestimating the juvenile offending rate. There is no reason to believe, however, that mixed-gender or mixed-race groups occur more often in a particular race or gender group and that omitting them would lower the rates of one group relative to another. Hence, comparisons of the race- and gender-specific rates should be appropriate. The strategy of making multiple estimates was not followed for gender- and race-specific rates because it would make presentation of the data too complex and the omission of the mixed groups data did not make as much difference in these rates as it did in the age-specific rates.

\section{Series Incidents}

A series incident refers to a procedure developed by the Census Bureau and used in the NCVS that reduces the burden of collecting information on high-volume repeat victimization. When a respondent reports he or she was victimized more than five times in the past 6 months, when these events are similar, and when the respondent cannot report on the details of each, then the interviewer is instructed to note the number of incidents but only collect detailed information on the most recent event. Because the Bureau of Justice Statistics, which sponsored the NCVS, is concerned about the accuracy of the information provided and, specifically, the number of events reported to have occurred, it excludes these events from annual rate estimates.

The estimates in this Bulletin include series incidents, but each one only as one incident and not as the number of incidents that the respondent said occurred in the series. Although series incidents are a small part of annual victimization rates, when they are weighted by the number of individual incidents occurring in them, they become more consequential. There is reason to believe that the number of events reported as occurring in series incidents is too high, but there is also reason to believe that some of these reports of high-volume repeat victimization are accurate. Including series incidents as one crime probably contributes to an underestimate of the juvenile offending rate, but the amount it contributes is unclear. ${ }^{4}$

In sum, the procedures used to take account of missing data, co-offending, and series incidents all contribute to the underestimation of offending rates. The agespecific rates are least affected by the procedural peculiarities of the NCVS because all mixed-group offending was included in these estimates. As a result, for the age-specific rates, only missing data and the handling of series incidents contribute to the underestimate. The race- and gender-specific rates are more substantial underestimates because some mixed-offending groups (those perfectly balanced in terms of race and gender) are omitted. This should not affect comparisons of rates across race and gender groups.

4 The vast majority of series incident victimizations involve domestic violence and crimes at work (e.g. assaults and thefts that occur at work) (Dodge, 1987; Lynch, Berbaum, and Planty, 1999). These events seldom involve juveniles. Approximately 12 percent of series incidents take place at school, and these are more likely to involve juveniles (Lynch, Berbaum, and Planty, 1999).
- Third, some reason exists to believe that the response errors in the NCVS may be less severe and better understood than those in self-report surveys of offending. Respondents to self-report surveys of offending may have substantial reasons for not responding accurately or truthfully-they may be concerned about repercussions or may want to convey a certain image (Thornberry and Krohn, 2000). The victim does not have the same self-interest in reporting about the attributes of offenders. To be sure, there are a number of known response errors in the NCVS that influence the reporting of victimization events, and incomplete reporting of crimes will lead to distortions in the description of offenders (Biderman and Lynch, 1991); however, it seems likely that estimates of offending are affected less by these sources of error than by the clear self-interest for strategic response in self-report surveys of offending.

- Finally, the NCVS includes a great deal of detailed information on individual crime events. In contrast, surveys of offending behavior are less concerned with describing individual crime incidents than with estimating the prevalence of offending over a given period of time. This information on the social context of offending (e.g., where the crime occurred, who was present, the number of offenders) can provide a description of offending that is simply not available in existing surveys of offending behavior. ${ }^{3}$

The NCVS also has some clear limitations for estimating offending rates:

- First, the NCVS asks very few questions about the attributes of offenders. Respondents are asked about the age, race, sex, and number of offenders and about their relationship to the offender. Surveys of offenders, obviously, can provide much more detailed information about the offender.

$\checkmark$ Second, some researchers question the ability of victims to provide reliable information on offenders, even in violent crimes. Although the race and gender of offenders may be relatively easy to identify, the same is not the case for age-for example, it may be difficult to make the distinction between a 21-yearold adult and a 17-year-old juvenile.

- Third, design features of the NCVS may also limit its utility for describing the offender population accurately. The fact that the NCVS only interviews victims 12 years of age and older will probably result in an underestimate of the offending rate for juveniles, especially the offending rate for children 
younger than 12 who are most likely to prey upon younger victims (Singer, 1981). However, because these younger victims are often victimized by adult caretakers (e.g., in sex offenses), interviewing these child victims could also increase the proportion of older offenders recorded in the data.

- Fourth, the NCVS asks about only a narrow range of crimes, and it can only produce offending rates for those types of crime.

- Fifth, the NCVS cannot be used to produce prevalence estimates of offending behavior because offenders cannot be linked across crime incidents.

Readers should keep these strengths and weaknesses in mind as they consider the offending rates presented in the following sections.

\section{Trends in Offending Rates Since 1980}

The offending rates presented here are estimated with data from the NCVS. Overall trends are reported along with separate trends by gender and race. Gender and race were chosen for separate consideration because these are the only attributes of offenders included in both the UCR and the NCVS.

Offending rates since 1980 , by adult co-offending status. In the period 1980 to 1998, the juvenile offending rate for serious violent crimes was, on average, somewhere between 44 and 75 victimizations by juvenile offenders per 1,000 persons ages 12 to 17 in the U.S. population. The lower estimate excludes all co-offending with adults, while the higher estimate includes all offenses in which there was co-offending with adults (see discussion of co-offending in "Computing Offending Rates With the NCVS" on pages 4-5). Over the period 1980 to 1998 , almost half the offending by juveniles was done in concert with persons perceived by victims to be adults. ${ }^{4}$

From a high in 1981, the offending rate (whether including or excluding adult cooffending) decreased until approximately 1988, when it began to increase sharply and stayed relatively high until 1994. At that point, it decreased sharply through 1998 (figure 4).

Including adult co-offending, the offending rate for serious violent crimes was 80 per 1,000 in 1981. It dropped to 56 per 1,000 by 1987 but then rose sharply to 78 per 1,000 in 1988.5 It remained near this level until 1992, when it rose to 89 per 1,000 , later peaking at 120 per 1,000 in 1993 . In 1994 , the rate began to decline until it reached 51 per 1,000 in 1998.

The contours of the trend are reasonably similar when co-offending with adults is excluded. From 44 per 1,000 in 1981, the juvenile offending rate (excluding adult co-offending) for serious violent crimes dropped to around 31 per 1,000 in 1982, where it hovered through 1987. In 1988, it increased to 36 per 1,000, then increased sharply a few years later, reaching 91 per 1,000 in 1993 . Thereafter, the rate declined to 36 per 1,000 in 1998 .

When adult co-offending incidents are examined separately, a very sharp increase in adult co-offending between 1987 and 1988 is revealed (71 percent). This compares with a 16-percent increase in juvenile-only offending. The adult co-offending rate dropped dramatically from 1991 to 1992 (a 38-percent decrease), while the juvenileonly rate increased. This suggests that adult co-offending contributed disproportionately to the increases in total juvenile offending in the late 1980s but did not drive the decreases in total juvenile offending in the mid-1990s. While adult cooffending dropped dramatically between 1991 and 1992, this decrease was offset by increases in juvenile-only offending. It was not until later in the decade (approximately 1994) that juvenile-only offending began to decrease markedly.

Offending rates since 1980 , by gender. Over the period 1980 to 1998 , the average offending rate for serious violent crimes was 8 to 11 times higher (depending on whether adult co-offending is excluded or included) for male juveniles than female juveniles. Excluding adult co-offending, the average offending rates for male juveniles and female juveniles were 68 per 1,000 and

Figure 4: Juvenile Offending Rates for Serious Violent Crimes, by Adult Co-Offending Status: 1980-98

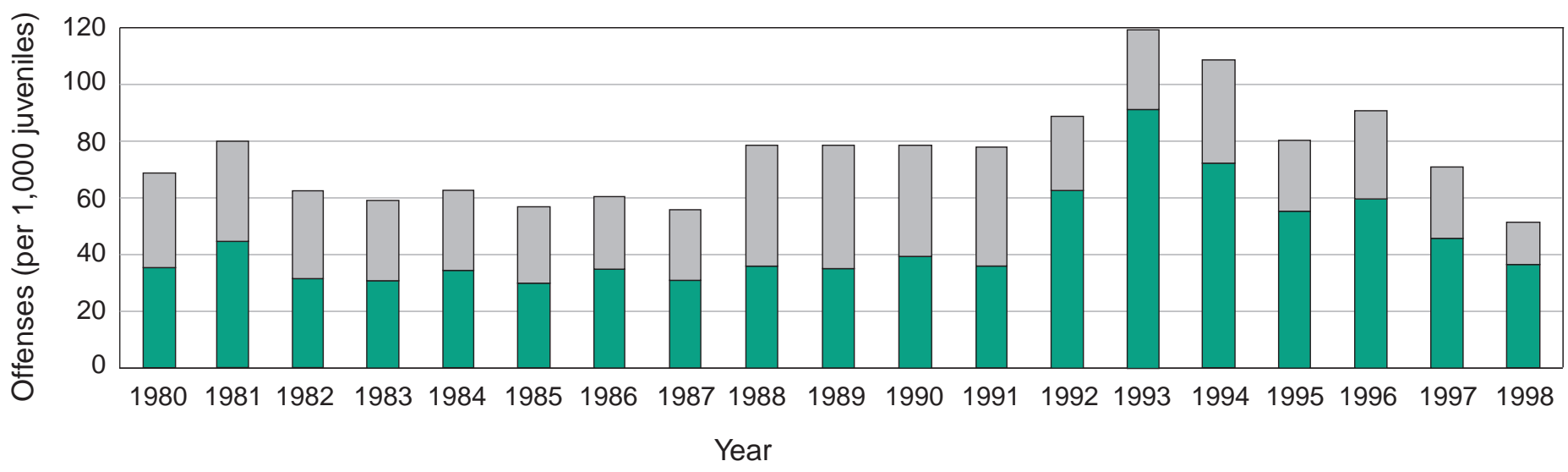

Without adult co-offending

With adult co-offending

Sources: U.S. Department of Justice, Bureau of Justice Statistics, National Crime Surveys: National Sample 1979-87 (computer file); National Crime Surveys: National Sample 1986-91 (computer file); National Crime Victimization Survey 1992-98 (computer file). 
8 per 1,000 , respectively. Including adult co-offending, the offending rate for male juveniles was, on average, 122 per 1,000 compared with 11 per 1,000 for females. Figure 5 shows the juvenile offending rates for serious violent crimes by adult cooffending status and gender for the years 1980 to 1998 .

Including adult co-offending, the offending rate for male juveniles was high in 1981 (140 per 1,000) and declined unevenly to a low of 88 per 1,000 in 1985 . The rate increased slowly in 1986, dramatically increased to 135 per 1,000 in 1988 , and reached a high of 181 per 1,000 in 1993 . Thereafter, it declined steadily to a low of 83 per 1,000 in 1998 . These trends are similar when co-offending with adults is excluded from the rates.
The trends in the female offending rate (either including or excluding adult cooffending) exhibit the same general movements from highs in the first half of the 1980 s to lows in the second half of the 1980 s to highs in the early 1990 s and declines thereafter. These movements are more erratic than the trends in male offending, in large part because the female rate is so low in general.

The ratio of male-to-female offending rates for serious violent crimes is greater when adult co-offending is included than when it is excluded. On average, during the period, the total offending rate (including adult cooffending) for male juveniles was 11 times that for female juveniles. When adult cooffending is excluded, the ratio decreases to 8 . This suggests that male juveniles are more likely than female juveniles to engage in serious violent co-offending with adults.

The overrepresentation of males in serious violent offending decreased over time. Excluding adult co-offending, from 1980 to 1986, male juveniles, on average, were engaged in serious violent offending at 16 times the rate of female juveniles. In the period 1993 to 1998 , this ratio decreased to 8 . This decrease resulted more from an increase in the offending rate of female juveniles than a decrease in the offending rate of male juveniles.

Offending rates since 1980 , by race. Over the period 1980 to 1998, the average offending rate for serious violent crimes was 3.4 to 4.1 times higher (depending on whether adult co-offending is excluded or included) for black juveniles than white

\section{Figure 5: Juvenile Offending Rates for Serious Violent Crimes, by Adult Co-Offending Status and Gender: 1980-98}

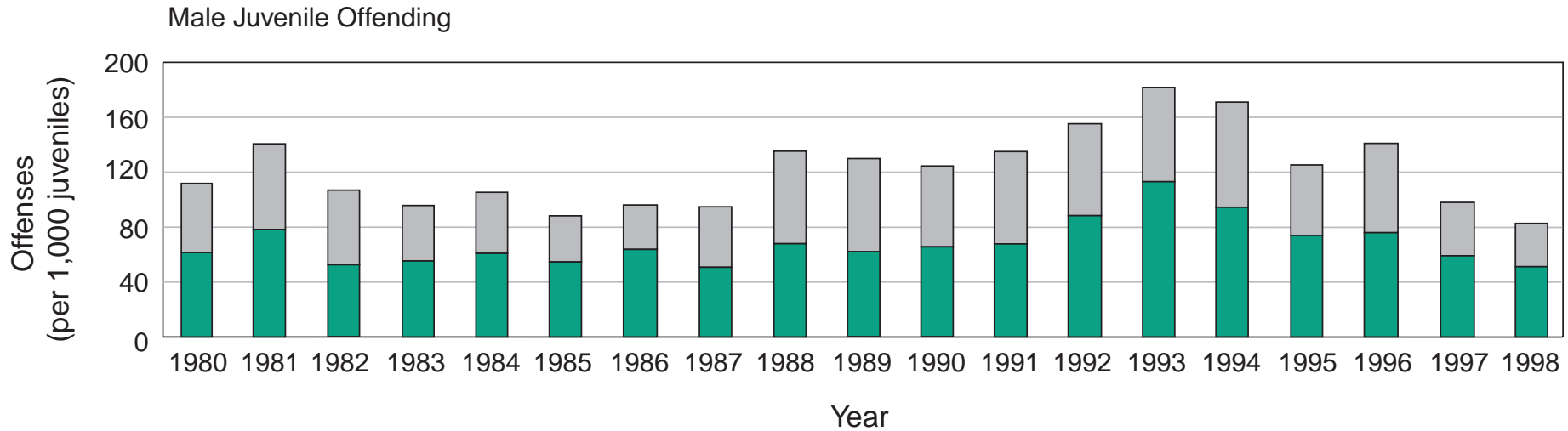

Female Juvenile Offending

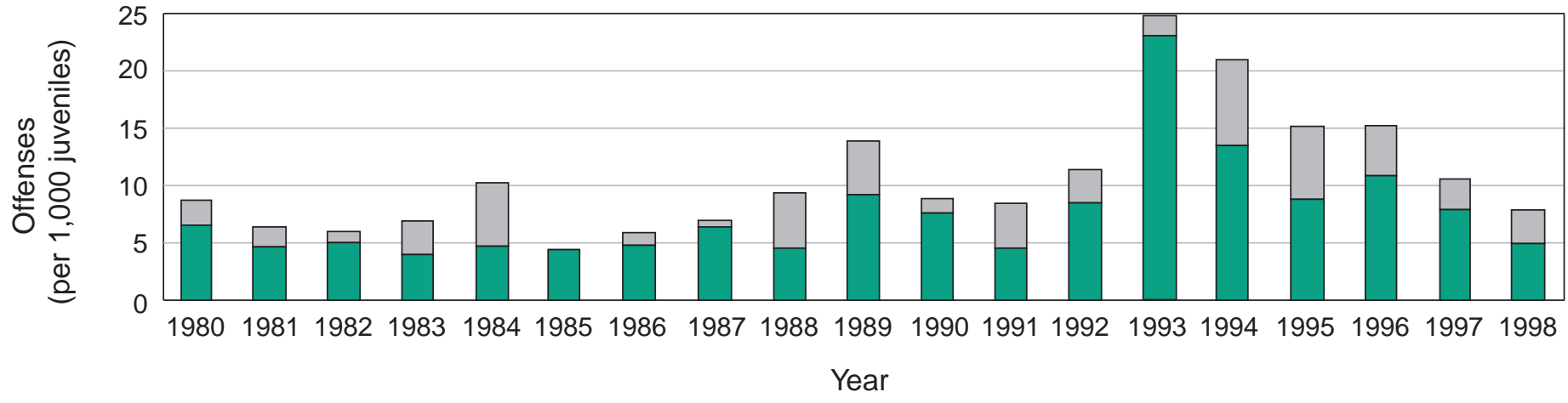

Without adult co-offending

With adult co-offending

Sources: U.S. Department of Justice, Bureau of Justice Statistics, National Crime Surveys: National Sample 1979-87 (computer file); National Crime Surveys: National Sample 1986-91 (computer file); National Crime Victimization Survey 1992-98 (computer file). 
juveniles. The average offending rate for black juveniles was between 96 per 1,000 (excluding adult co-offending) and 167 per 1,000 (including adult co-offending) compared with between 28 and 41 per 1,000 , respectively, for white juveniles.

Adult co-offending was a more prominent feature of serious violent offending for black juveniles than for white juveniles. On average, over the period 1980 to 1998 , the ratio of adult co-offending to total juvenile offending was 0.31 for whites (approximately 1 instance of adult co-offending for every 3 instances of juvenile offending) and 0.43 for blacks (more than 2 instances of adult co-offending for every 5 instances of juvenile offending).
Adult co-offending accounted for a disproportionate amount of the increase in serious violent offending for black juveniles in the late 1980s (figure 6). Rates of adult co-offending for blacks increased by 60 percent between 1986 and 1987 and by 37 percent from 1988 to 1989 . The juvenileonly offending rates for blacks during this period increased much less (increasing 15 percent from 1986 to 1987 and decreasing 2 percent between 1988 and 1989). Later, between 1991 and 1993, this trend was reversed as the increases in juvenile-only offending were larger than the increases in adult co-offending. ${ }^{6}$

\section{Trends in Offending Rates Since 1993}

The longer term trends reported in the previous section were limited to broad categories of gender and race because the adjustments that must be applied to pre-1992 NCVS data are more reliable for larger groups than smaller ones. In the period 1993 to 1998, no adjustments need to be applied, so it is possible to examine more specific demographic and offense categories. Moreover, because some of the more pronounced decreases in arrests and offending occurred in this period, a more detailed examination may be enlightening.

\section{Figure 6: Juvenile Offending Rates for Serious Violent Crimes, by Adult Co-Offending Status and Race: 1980-98}

\section{Black Juvenile Offending}

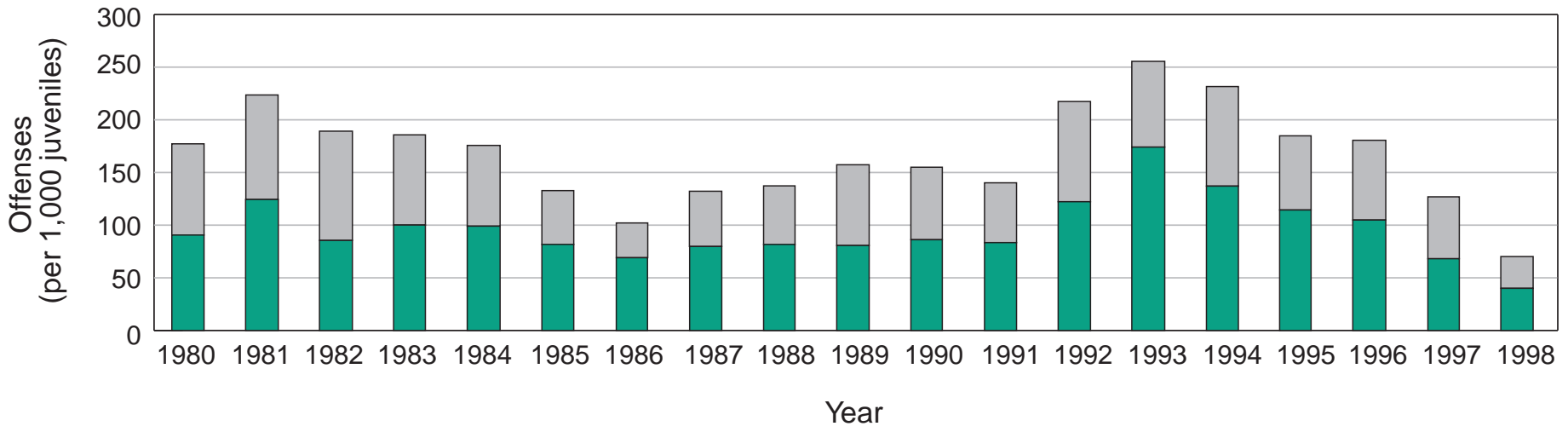

White Juvenile Offending

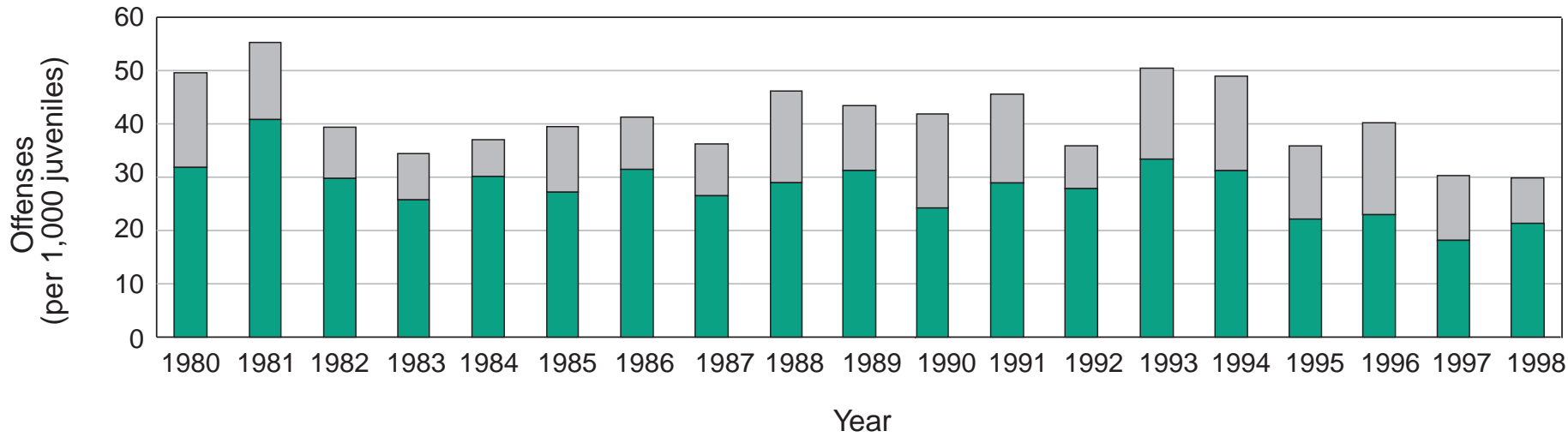

Without adult co-offending

With adult co-offending

Sources: U.S. Department of Justice, Bureau of Justice Statistics, National Crime Surveys: National Sample 1979-87 (computer file); National Crime Surveys: National Sample 1986-91 (computer file); National Crime Victimization Survey 1992-98 (computer file). 
Offending rates since 1993 , by specific crime category. The decrease in serious violent offending between 1993 and 1998 was greatest for robbery and, in some cases, less for aggravated assault (figure 7). ${ }^{7}$ In 1993, the total juvenile offending rate (including adult co-offending) for robbery was 46.6 per 1,000 . This fell to 14.8 per 1,000 by 1998 , a decrease of 68 percent. When adult co-offending is excluded, the rate decreased from 30.4 per 1,000 in 1993 to 10.7 per 1,000 in 1998 , a decrease of 64 percent. The total juvenile offending rate (including adult co-offending) for aggravated assault decreased from 67.4 per
1,000 in 1993 to 30.9 per 1,000 in 1998 , or 54 percent. When adult co-offending is excluded, the rate decreased from 40.9 to 14.7, or 64 percent. Therefore, for both robbery and aggravated assault, with adult co-offending included or excluded, the rate of serious juvenile violence in 1998 was just one-third of its 1993 level. These declines in offending rates for robbery and aggravated assault are greater than the corresponding declines in the juvenile arrest rates for robbery (41 percent) and aggravated assault (16 percent).

Figure 7: Juvenile Offending Rates for Robbery and Aggravated Assault, by Adult Co-Offending Status: 1993-98
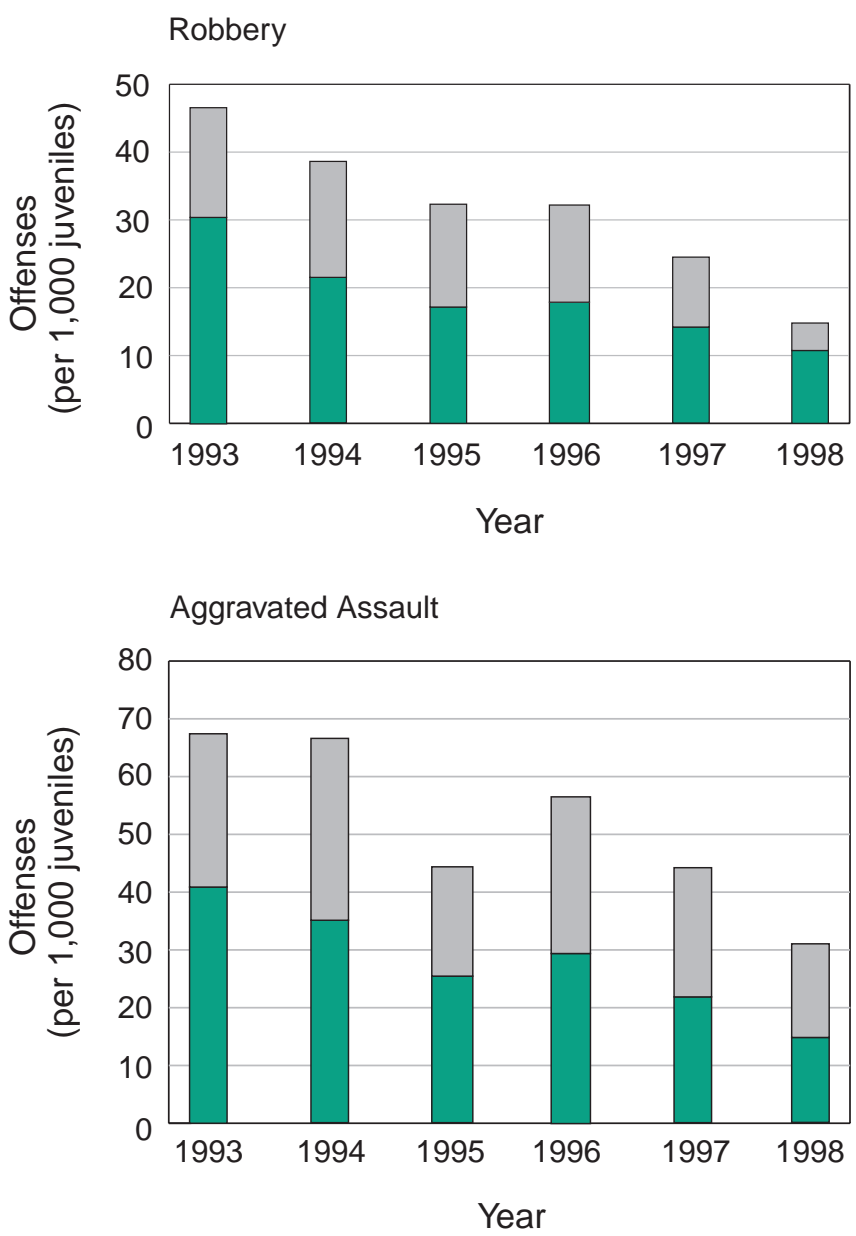

Without adult co-offending

With adult co-offending

Sources: U.S. Department of Justice, Bureau of Justice Statistics, National Crime Victimization Survey 1992-98 (computer file).

\section{An Important Distinction}

When interpreting the rates presented in this Bulletin, it is important to appreciate the difference between offending rates and offender rates. An offending rate estimates the number of offenses committed by a given population. The offending rate is often referred to as the incidence rate. An offender rate estimates the number of persons in a given population who have committed one or more crimes. The offender rate is often referred to as the prevalence rate.

The difference between these rates is that prevalence rates do not take account of repeated offending by the same person, whereas incidence rates do. Once a person has committed one offense, that person is counted in the numerator of the offender rate and subsequent offending by that person will not affect the rate. In contrast, the numerator of the offending rate will increase whenever a new offense is committed by a member of the at-risk population. One of the advantages of a prevalence rate is that it cannot exceed 1.0 and provides an easily interpretable indicator of how many of the persons in a given group have offended in a given period of time. With a prevalence rate, one can say, for example, that 40 percent of male juveniles have offended in a year. An incidence rate, on the other hand, can exceed 1.0 if some members of the at-risk population commit more than one offense during the period. Incidence rates indicate the relative involvement of groups in offending or the relative contribution of a group to total offending while taking into account the size of the group. With an incidence rate, it is possible to say, for example, that males are twice as likely to engage in offending behavior as females, but impossible to say what proportion of each group engages in offending behavior.

Most of the indicators used in criminal justice are incidence rates, largely because it is difficult to identify repeat offenders or repeat victims, and doing so is essential for estimating prevalence rates. So the UCR crime rates published annually by the $\mathrm{FBI}$ are incidence rates, as are the victimization rates published by the Bureau of Justice Statistics. It is important to keep in mind the difference between incidence and prevalence rates. 
Offending rates since 1993 , by race and crime category. The decrease in overall serious violent offending was greater for black juveniles than for white juveniles from 1993 to 1998 , and this pattern was replicated for both robbery and aggravated assault (figure 8). For robbery, including adult co-offending, the offending rate for white juveniles decreased 46 percent (45 percent when adult co-offending is excluded) and the offending rate for black juveniles decreased 76 percent (77 percent excluding adult co-offending). The decrease in the offending rate (including adult co-offending) for white juveniles who committed aggravated assault was 49 percent (50 percent excluding adult co-offending) compared with 70 percent (79 percent excluding adult co-offending) for black juveniles.

Trends in co-offending since $\mathbf{1 9 9 3}$. It is possible, using NCVS data, to examine the contribution of co-offending to the total juvenile offending rate for serious violent crimes. Throughout the period 1993 to 1998 , the average annual juvenile offending rate was 87 offenses per 1,000. Lone offending accounted for 18 offenses per 1,000 , co-offending with other juveniles accounted for 42 per 1,000, and cooffending with adults accounted for 27 per 1,000. Overall, three-fourths of juvenile offending was co-offending, and more than

\section{Figure 8: Juvenile Offending Rates for Robbery and Aggravated Assault, by Adult Co-Offending Status}

and Race: 1993-98
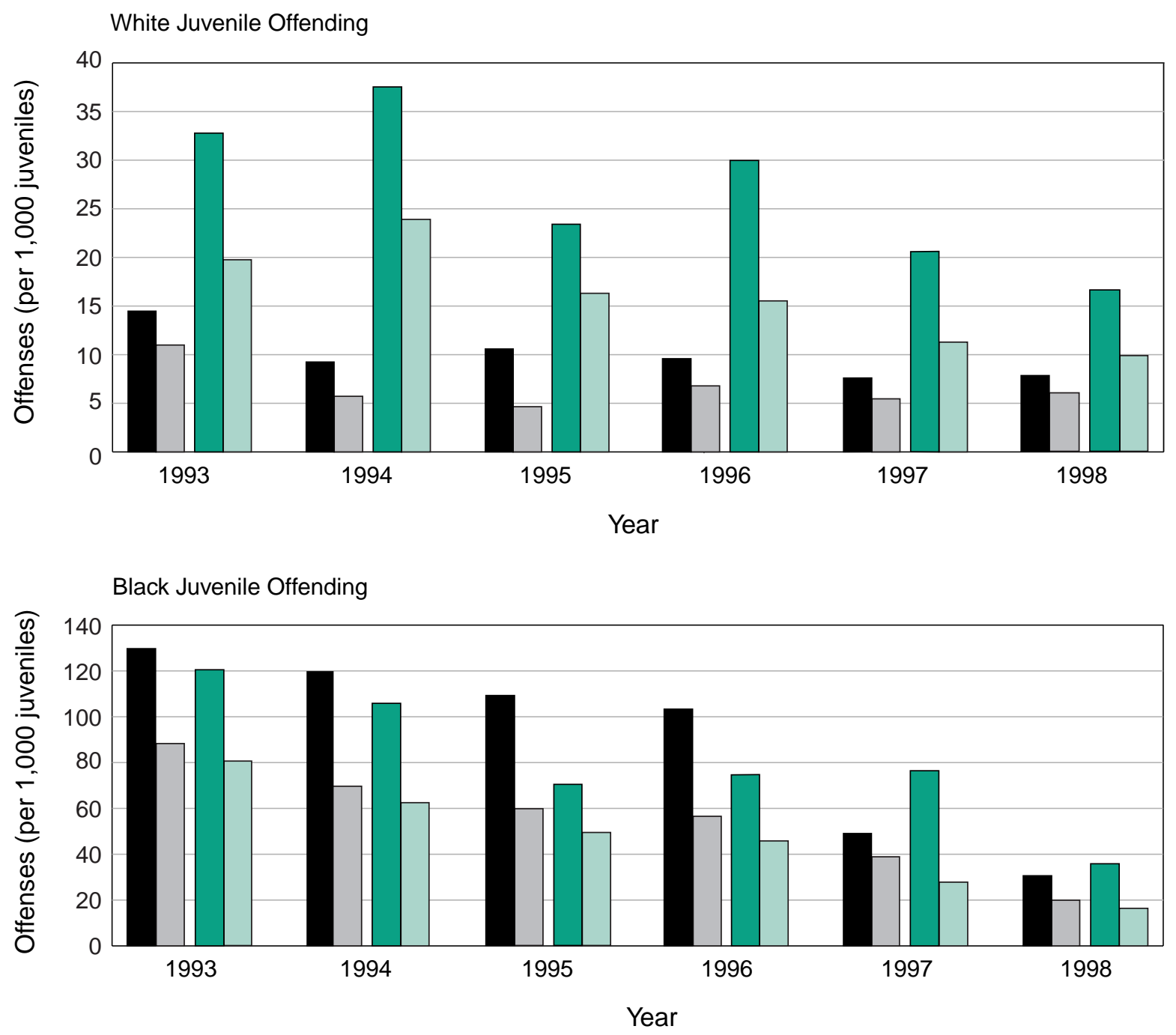

Robbery (including adult co-offending)

Aggravated assault (including adult co-offending)

Robbery (excluding adult co-offending)

Aggravated assault (excluding adult co-offending)

Sources: U.S. Department of Justice, Bureau of Justice Statistics, National Crime Victimization Survey 1992-98 (computer file). 


\section{Figure 9: Juvenile Offending Rates for Serious Violent Crimes, by Co-Offending Status: 1993-98}

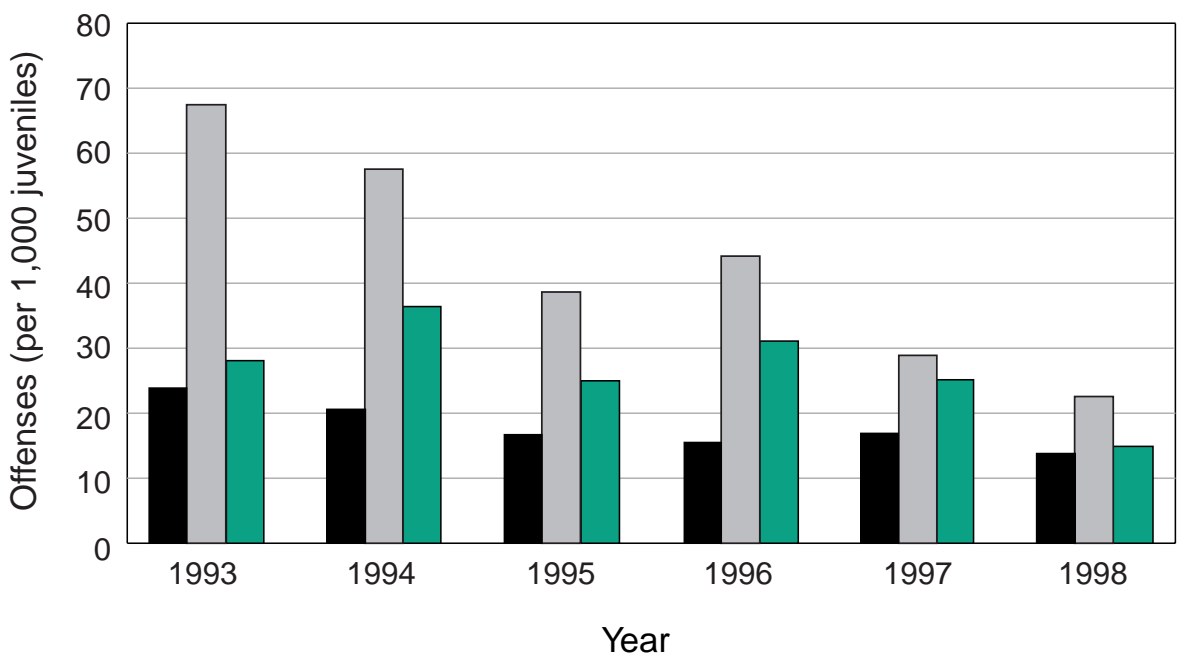

Lone offending

Co-offending with juveniles

Co-offending with adults

Sources: U.S. Department of Justice, Bureau of Justice Statistics, National Crime Victimization Survey 1992-98 (computer file).

\section{Table 1: Average Juvenile Offending Rates for Serious Violent Crimes,} by Gender and Co-Offending Status: 1993-98

\begin{tabular}{lcccc} 
& \multicolumn{4}{c}{ Offending Rate (per 1,000 juveniles) } \\
\cline { 2 - 5 } Gender & $\begin{array}{c}\text { Committed } \\
\text { Alone }\end{array}$ & $\begin{array}{c}\text { Committed } \\
\text { With Adult }\end{array}$ & $\begin{array}{c}\text { Committed } \\
\text { With Juvenile }\end{array}$ & $\begin{array}{c}\text { All } \\
\text { Incidents }\end{array}$ \\
\hline Male & 30.3 & 55.4 & 47.7 & 133.3 \\
Female & 4.7 & 4.3 & 6.8 & 15.8
\end{tabular}

one-third of the co-offending was with adults.

All categories-lone offending, co-offending with juveniles, and co-offending with adults_of the juvenile offending rate for serious violent crimes decreased during 1993-98 (figure 9). The total juvenile offending rate for serious violent crimes decreased 57 percent, from 119 per 1,000 to 51 per 1,000. The decrease in offending rates between 1993 and 1998 was greater for co-offending than for lone offending. The offending rate for lone offenders who committed serious violent crimes decreased by 42 percent over the period, from 24 per 1,000 to 14 per 1,000 . The cooffending rate (including both juvenile and adult co-offenders) declined 61 percent, from 96 to 37 per 1,000 . The juvenile co-offending rate decreased more than the adult co-offending rate (67 percent and 47 percent, respectively).

Co-offending is somewhat greater among male juveniles than female juveniles (table 1). On average, throughout the period 1993 to 1998 , approximately 78 percent of the male juvenile offending rate for serious violent crimes involved co-offending compared with 70 percent for female juveniles. Co-offending for male juveniles was evenly split between adult co-offending (42 percent of all incidents) and juvenile co-offending (35 percent of all incidents). However, for female juveniles, a greater proportion of all serious violent crimes involved juvenile co-offenders (43 percent of all incidents) than adult co-offenders (27 percent of all incidents).
Decreases in serious violent offending from 1993 to 1998 were greater for female juveniles (68 percent) than for male juveniles (55 percent). The decreases in lone offending and adult co-offending were slightly greater for female juveniles (46 and 61 percent respectively) than male juveniles (42 and 59 percent, respectively). ${ }^{8}$ The largest differences between the genders occurred in co-offending with other juveniles, where the decrease for male juveniles was 62 percent compared with a 92-percent decrease for female juveniles. Figure 10 shows the 1993-98 rates of lone offending, juvenile co-offending, and adult co-offending for male and female juveniles.

Between 1993 and 1998, lone offending represented a much higher proportion of the offending rate for white juveniles than for black juveniles (table 2). Thirty-one percent of the white juvenile offending rate for serious violent crimes involved lone offending, 37 percent involved co-offending with adults, and 32 percent involved co-offending with juveniles. In contrast, only 20 percent of the black juvenile offending rate for serious violent crimes involved lone offending, 39 percent involved co-offending with adults, and 41 percent involved cooffending with juveniles.

Between 1993 and 1998, the rate of serious violent offending decreased 72 percent for black juveniles and 40 percent for white juveniles. Lone offending dropped by about the same proportion for both races ( 42 percent for black juveniles and 43 percent for white juveniles). Co-offending with adults decreased more for black juveniles than for white juveniles (63 percent and 50 percent, respectively). The largest difference was for co-offending with juveniles, which decreased 90 percent for black juveniles and 29 percent for white juveniles. Figure 11 shows the 1993-98 rates of lone offending, co-offending with juveniles, and co-offending with adults for white and black juveniles.

In sum, much of the serious violent offending by juveniles is done in groups, and juveniles are as likely to co-offend with an adult as with other juveniles (based on victims' perceptions of offender age). Males engage in co-offending more than females, and blacks more than whites. Between 1993 and 1998, rates of co-offending have decreased faster than rates of lone offending. These decreases in co-offending have been more pronounced for blacks than for whites. 
Figure 10: Juvenile Offending Rates for Serious Violent Crimes, by Gender and Co-Offending Status: 1993-98

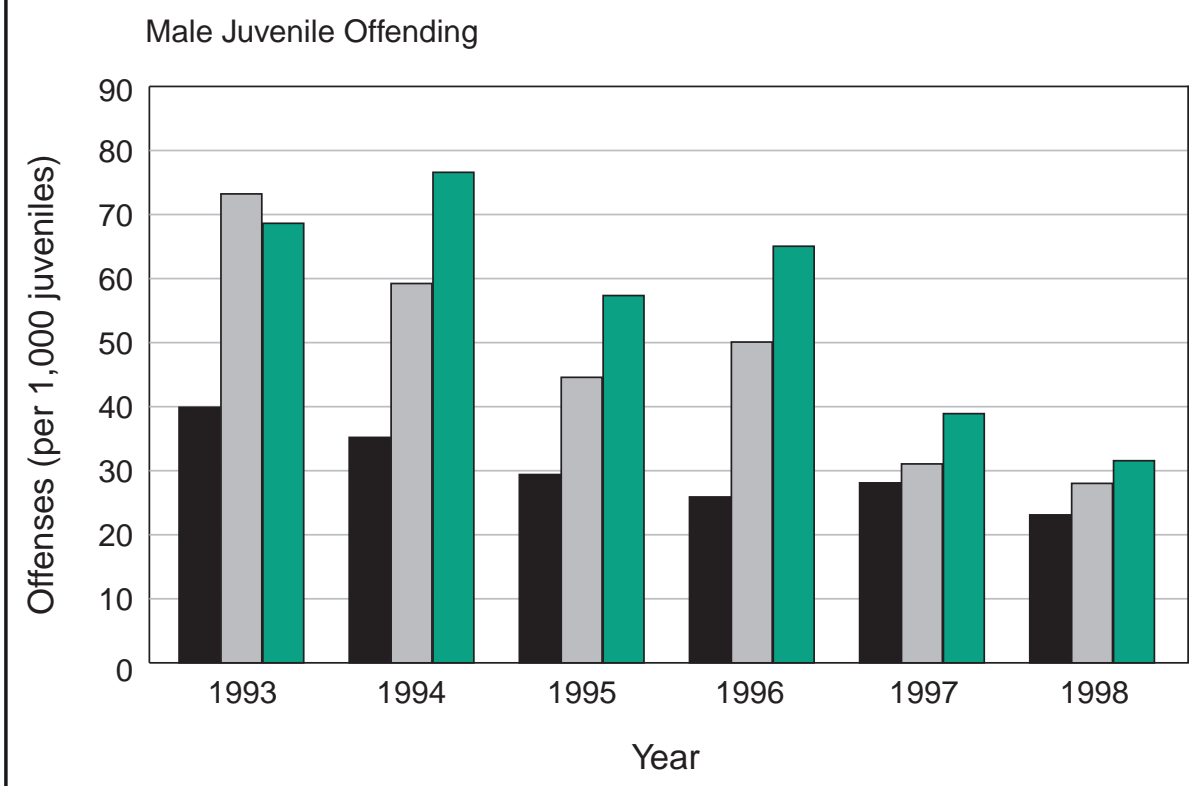

Female Juvenile Offending

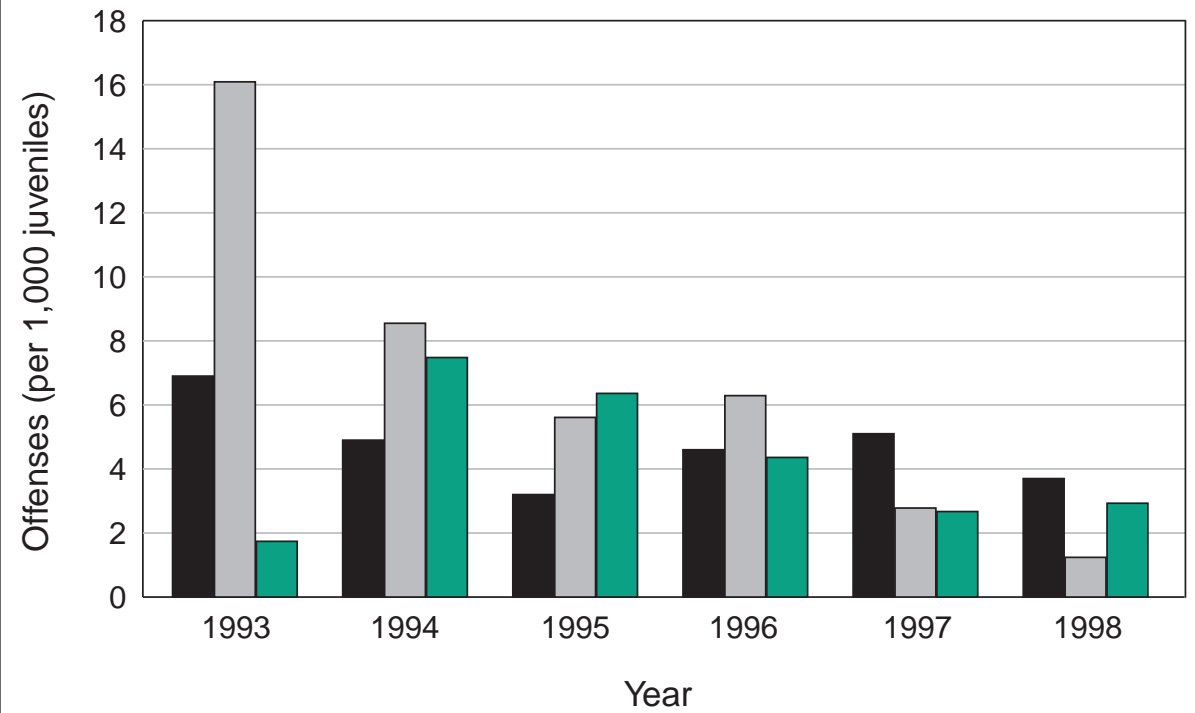

Lone Offending

Co-offending with juveniles

Co-offending with adults

Sources: U.S. Department of Justice, Bureau of Justice Statistics, National Crime Victimization Survey 1992-98 (computer file).

\section{Comparing UCR and NCVS Estimates of Offending Rates}

As noted previously, UCR data indicate that the average annual juvenile arrest rate for serious violent crimes during 1980-98 was 5 per 1,000 persons ages 12 to 17 . NCVS data indicate that, depending on whether adult co-offending is excluded or included, the juvenile offending rate for the same crimes during the same period was 9 to 15 times the juvenile arrest rate (44 per 1,000 excluding adult co-offending and 75 per 1,000 including adult co-offending). This is not unreasonable, considering that only 20 percent of the violent crimes by juveniles reported in victim surveys are reported to the police and that, of those crimes reported to the police, approximately 50 percent lead to an arrest.

The broad trends in the UCR arrest data and NCVS offending data are similar. Both show decreases in the early 1980s followed by an increase later in the decade, with continued high rates until the mid-1990s, when rates dropped dramatically (figure 1 and figure 12). Arrest rates reached a low point in 1987 but increased steadily thereafter until 1994, when they began to drop. Offending rates reached a low point in 1987 and then increased in 1988. These higher rates persisted until 1994, when they began to trend downward.

The increases observed in the mid-1980s were similar for offending rates and arrest rates, but the decreases in the 1990s were greater for offending rates than for arrest rates. Between 1987 and 1993, the juvenile arrest rate increased about 70 percent, while the juvenile offending rate increased between 114 percent (including adult co-offending) and 195 percent (excluding adult co-offending). Regardless of the assumptions that are made about adult cooffending, the increase in the offending rate was greater than the increase in the arrest rate. Similarly, the juvenile arrest rate for serious violent crimes declined 27 percent from 1993 to 1998 , while the juvenile offending rate for serious violent crimes declined between 57 percent (including adult co-offending) and 60 percent (excluding adult co-offending) during the same period. The increases and decreases in the offending rate during 1980-98 were much greater than the increases and decreases in the arrest rate. 
Table 2: Average Juvenile Offending Rates for Serious Violent Crimes, by Race and Co-Offending Status: 1993-98

\begin{tabular}{lcccc} 
& \multicolumn{4}{c}{ Offending Rate (per 1,000 juveniles) } \\
\cline { 2 - 5 } Race & $\begin{array}{c}\text { Committed } \\
\text { Alone }\end{array}$ & $\begin{array}{c}\text { Committed } \\
\text { With Adult }\end{array}$ & $\begin{array}{c}\text { Committed } \\
\text { With Juvenile }\end{array}$ & $\begin{array}{c}\text { All } \\
\text { Incidents }\end{array}$ \\
\hline White & 12.0 & 14.4 & 12.2 & 38.6 \\
Black & 34.9 & 68.5 & 71.6 & 174.9
\end{tabular}

Figure 11: Juvenile Offending Rates for Serious Violent Crimes, by Race and Co-Offending Status: 1993-98

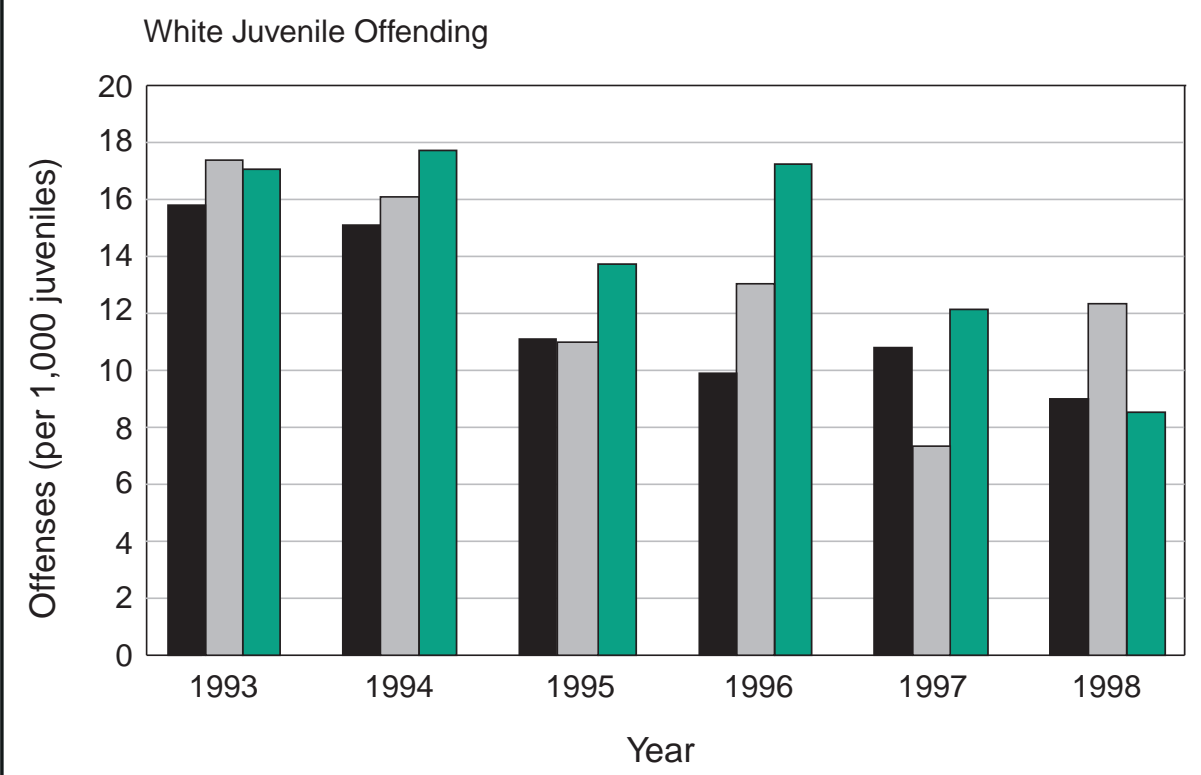

Black Juvenile Offending

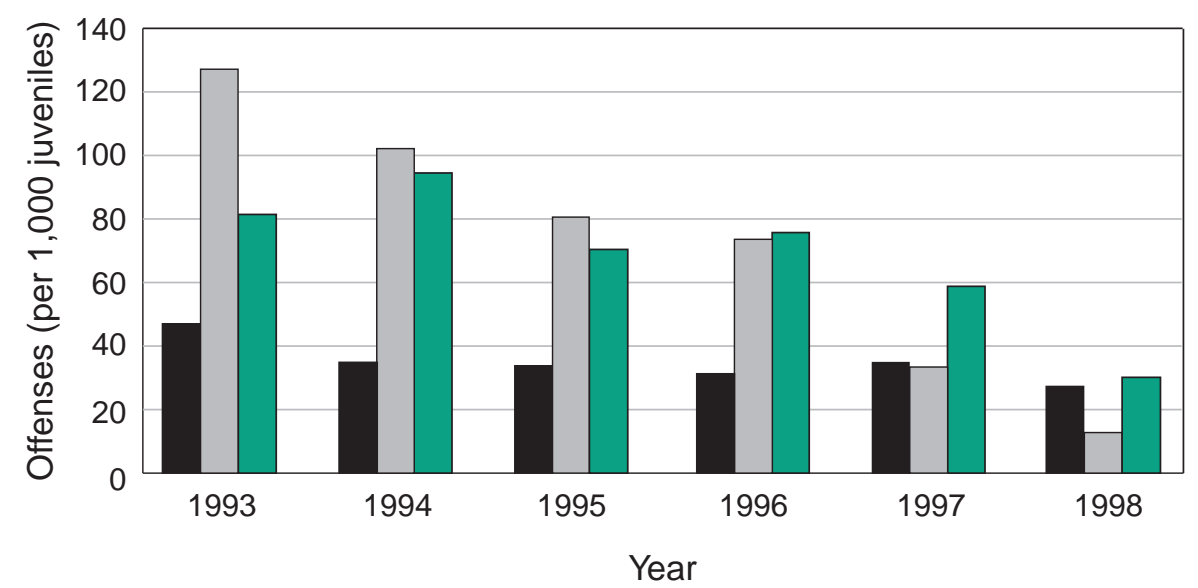

Lone Offending

Co-offending with juveniles

Co-offending with adults

Sources: U.S. Department of Justice, Bureau of Justice Statistics, National Crime Victimization Survey 1992-98 (computer file).

\section{Comparison by Gender}

The data on both arrests and offending showed higher rates of serious violent offending for male juveniles than female juveniles. The overrepresentation of males was greater in the data on offending than in the arrest data. This means that, given their offending rates, male juveniles were underrepresented and female juveniles were overrepresented in arrest data. The disproportionality of male offending decreased over time but more so in arrest data than in offending data.

The ratio of male juveniles to female juveniles was lower in the arrest data than in the offending data. For serious violent crimes (i.e., forcible rape, robbery, and aggravated assault), the average ratio of male juveniles to female juveniles was 6.8 in the arrest data but ranged between 9 (excluding adult co-offending) and 11.5 (including adult co-offending) in the offending data. This discrepancy may be due to the fact that more crimes involving intimates (e.g., siblings, dating couples) are reported in the NCVS than in police data systems. There may be more male offenders in these crimes than in other types of violent crimes, resulting in a higher ratio of male to female offenders. Domestic violence, for example, is more often committed by males than females.

Between 1980 and 1998, the male-female ratio for juvenile arrest rates for serious violent crimes decreased from 8.3 to 4.5 (figure 13). The male-female ratio for juvenile offending rates for serious violent crimes has also generally decreased, but not as consistently and not as much as the arrest rate ratio. The male-female ratio for offending rates (with adult co-offending included) decreased from a high of 22 in 1981 to 10.5 in 1998 (with a low of 7.3 in 1993). When adult co-offending is excluded, the ratio was 16.8 in 1981 and 10.4 in 1998 (with a low of 4.9 in 1993). Although this seems broadly consistent with the arrest data, the male-female ratio in offending has fluctuated throughout the period. Indeed, this ratio increased from 1996 to 1998 in the offending data, while it continued to decline in the arrest data.

One of the factors contributing to the decline in the overrepresentation of males in juvenile arrest rates for serious violent crimes has been the steady increase in the arrest rates for female juveniles since 1980 . Between 1980 and 1998, the female juvenile arrest rate for serious violent crimes increased 89 percent, from 0.9 per 1,000 to 1.7 per 1,000 (figure 2). The arrest rate for 
Figure 12: Juvenile Arrest and Offending Rates for Serious Violent Crimes, by Adult Co-Offending Status: 1980-98

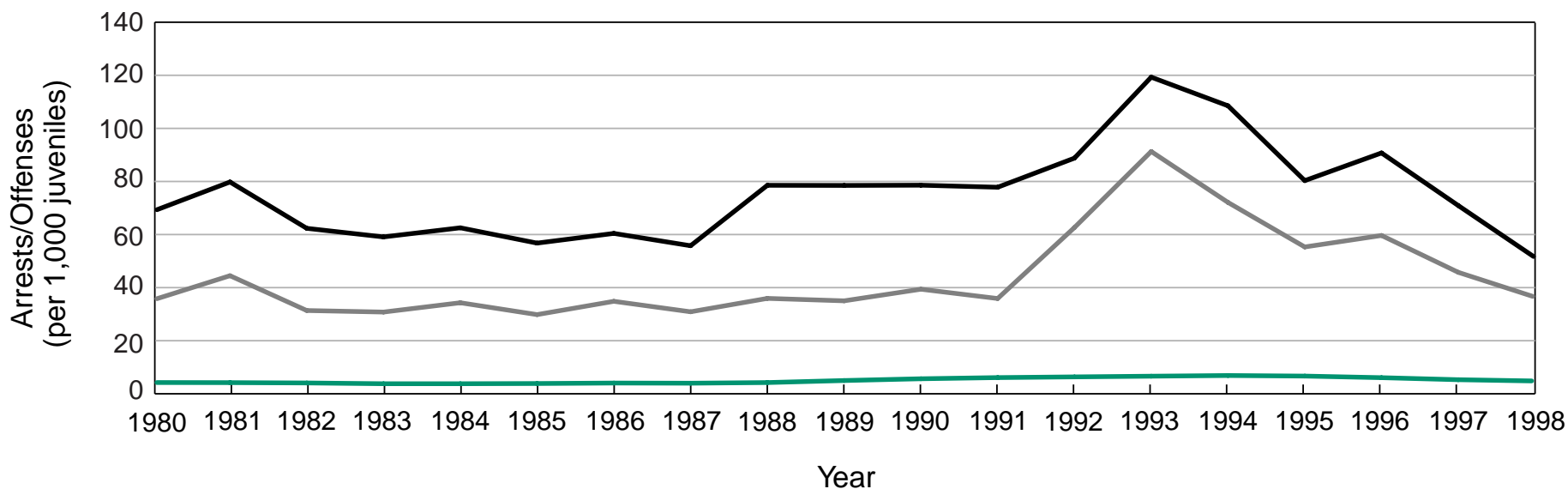

- Juvenile offending
(including adult co-offending)

- Juvenile offending
(excluding adult co-offending)

- Juvenile arrests*

* Due to the difference in scale between the arrest and offending rates presented in this figure, the rate for juvenile arrests appears relatively flat. Figure 1 presents this juvenile arrest data using a different scale which better shows the fluctuation in juvenile arrest rates during this period.

Sources: National Center for Juvenile Justice. U.S. Department of Justice, Bureau of Justice Statistics, National Crime Surveys: National Sample 1979-87 (computer file); National Crime Surveys: National Sample 1986-91 (computer file); National Crime Victimization Survey 1992-98 (computer file).

Figure 13: Male-Female Ratios for Juvenile Arrest and Offending Rates for Serious Violent Crimes, by Adult Co-Offending Status: $1980-98$

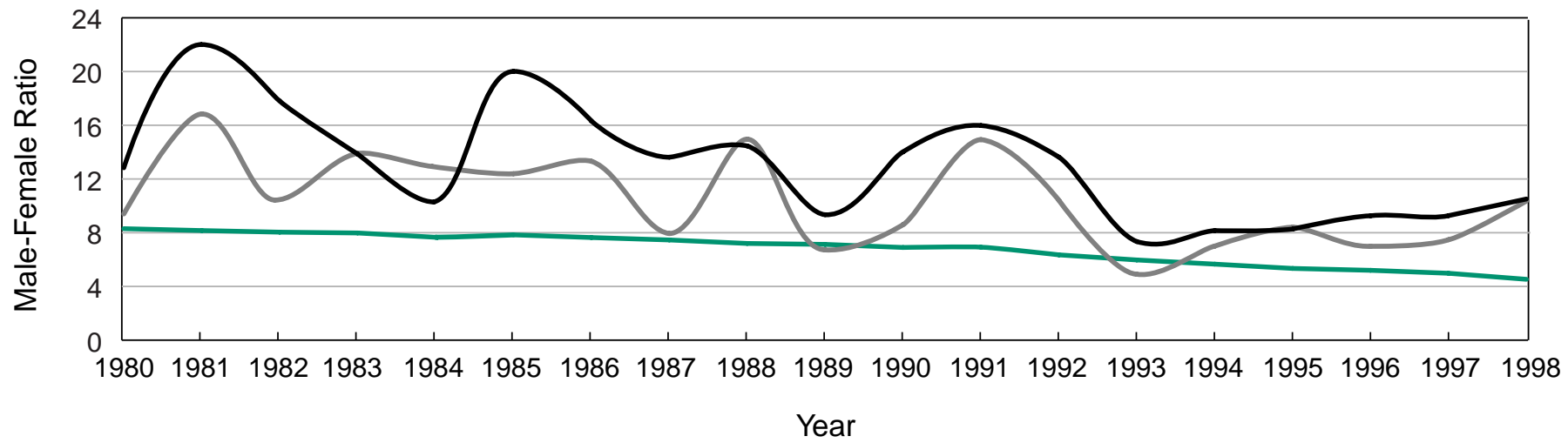

$\begin{array}{lll}\text { Offending rates } & - & \text { Offending rates } \\ \text { (including adult co-offending) } & \text { (excluding adult co-offending) }\end{array}$

Sources: National Center for Juvenile Justice. U.S. Department of Justice, Bureau of Justice Statistics, National Crime Surveys: National Sample 1979-87 (computer file); National Crime Surveys: National Sample 1986-91 (computer file); National Crime Victimization Survey 1992-98 (computer file).

male juveniles increased only 2 percent during the same period. Moreover, arrest rates for male juveniles fluctuated during this period, but arrest rates for female juveniles increased consistently throughout the 19 years. In contrast, female offending rates varied much more over time and did not show the steady increase found in the female arrest rates (figure 5).

\section{Comparison by Race}

The data on both offending and arrests showed that compared with white juveniles, black juveniles had much higher 
rates of involvement in serious violent crime. This disproportionality was greater in arrest rates than in offending rates. However, it decreased over time in both the arrest data and the offending data. Much of the overall decrease in the disproportionality of serious violent offending by black juveniles was the result of the large decrease in offending by blacks for these crimes that occurred after 1993.

During 1980-98, the average arrest rate for serious violent crimes was 5.7 times higher for black juveniles than for white juveniles. The black-white ratio for offending rates for serious violent crimes ranged from 4.1 (including adult co-offending) to 3.4 (excluding adult co-offending). Although blacks are overrepresented in both the offending data and the arrest data for $1980-98$, the overrepresentation is greater in the arrest data.

Over time, the black-white arrest rate ratio declined from a high of 6.9 in 1983 to 3.9 in 1998, or 43 percent (figure 14). The comparable offending ratio (including adult co-offending) decreased from a high of 6.1 in 1992 to 2.4 in 1998, or 61 percent. When adult co-offending is excluded from the offending rates, the ratio decreased from a high of 5.2 in 1993 to a low of 1.9 for 1998, or 63 percent.

In the period 1992-98, the black-white arrest ratio was quite similar to the blackwhite offending ratio. On average during this period, the black arrest rate was 4.9 times that of whites. The black offending rate was 4.2 times that of whites when adult co-offending is excluded and 4.6 times that of whites when adult cooffending is included.

The decrease in the overrepresentation of blacks in juvenile arrest rates for serious violent crimes resulted in part from the steady increase in arrest rates for white juveniles since the early 1980 s. The white juvenile arrest rate for serious violent crimes increased from 2.3 in 1980 to 4.2 in 1994 (figure 3), an increase of 83 percent. This rate only began to decrease noticeably in 1996. In contrast, the black juvenile arrest rate for serious violent crimes increased 64 percent during 1980-94, and, beginning in 1994, it decreased more sharply than the arrest rate for white juveniles. Looking at offending rates, the decrease in the racial disproportionality has resulted from decreases in black offending since 1990, not increases in white offending.

\section{Conclusion}

Examining serious violent offending through data gathered from victims provides a picture that is both similar to and different from that emerging from police arrest data. Not surprisingly, the volume of offending is much greater in the NCVS data than is indicated in the UCR arrest data. Depending on whether adult co-offending is excluded or included, offending rate estimates from the NCVS data are 9 to 15 times greater than the arrest rate estimate from the UCR data. Both sources of data show race and gender disproportionality in serious violent offending. Male juveniles offend at much higher rates than female juveniles. Black juveniles offend at much greater rates than white juveniles. The amount of gender disproportionality, however, is greater in the NCVS data than the UCR data, while the racial disproportionality is greater in the UCR data than the NCVS data. In other words, victims indicate that there are more male offenders (relative to female offenders) and more white offenders (relative to black offenders) than appear in police records.

\section{Figure 14: Black-White Ratios for Juvenile Arrest and Offending Rates for Serious Violent Crimes, by Adult Co-Offending Status: 1980-98}

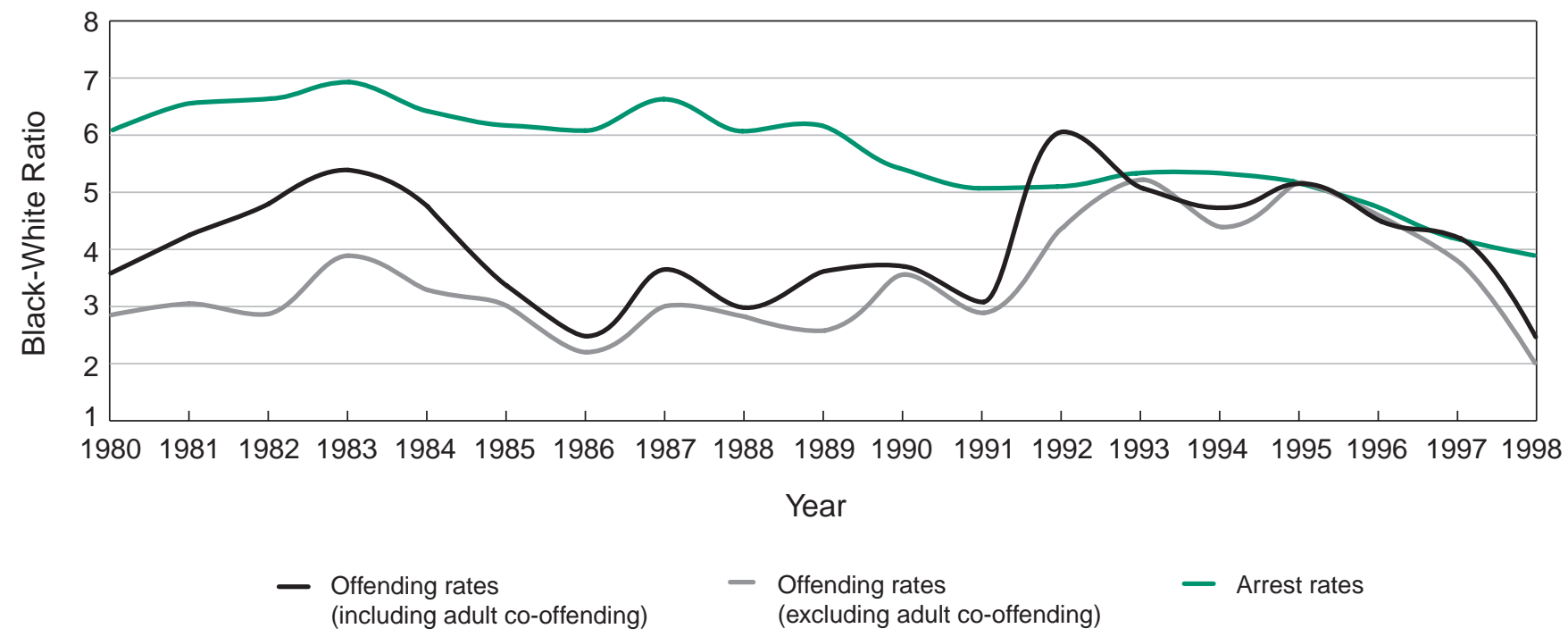

Sources: National Center for Juvenile Justice. U.S. Department of Justice, Bureau of Justice Statistics, National Crime Surveys: National Sample 1979-87 (computer file); National Crime Surveys: National Sample 1986-91 (computer file); National Crime Victimization Survey 1992-98 (computer file). 


\section{Adjusting NCVS Data}

As noted in the text, the methodology employed in the National Crime Victimization Survey (NCVS) was changed radically in 1992. As a result, data from the pre-1992 period, when the survey was known as the National Crime Surveys (NCS), must be adjusted to make them comparable to the more recent data. An adjustment of the data is possible because the old NCS and new (NCVS) designs were run in parallel for 18 months. Data from this overlap period can be used to compute the ratio of estimates from the post-1992 and pre-1992 designs. This ratio, in turn, can be used to adjust all the pre-1992 data to make them comparable to the post-1992 data (Kindermann, Lynch, and Cantor, 1997; Rand, Lynch, and Cantor, 1997; Lynch and Cantor, 1996).

The Bureau of Justice Statistics (BJS) has produced a ratio adjustment for major crime classes. BJS cautions, however, that this adjustment factor may not be suitable for adjusting trends for subpopulations (such as juveniles) or specific estimates other than victimization rates. Consequently, adjustment factors for offender trends have been specifically developed for the analysis presented in this Bulletin.

These adjustment factors were produced using the same methodology employed by Lynch and Cantor (1996) to determine the adjustments BJS used for gross victimization trends. Specifically, offending rates were estimated using the NCS and the NCVS data from the 1992 overlap. Significance tests were performed on the differences between the rate estimates from the old and new designs. When significant differences were found, further tests were employed for specific subpopulations. If, for example, the rates from the NCVS were significantly different from the NCS for both males and females, the significance of this difference was tested to determine whether specific ratio adjustments should be applied for each gender. Whenever significant differences between the designs were found, adjustment ratios were produced and applied to each subgroup. If these differences were not significant, then the same adjustment ratio was applied to all subgroups. The following are the adjustment ratios used in this Bulletin for offending rates overall, by gender, and by race.

Overall. The adjustment ratios for overall juvenile offending including adult co-offending are as follows: rape, not significant (ns); robbery, ns; aggravated assault, ns; simple assault, 2.02; total violence, 1.58. The adjustment ratios for juvenile offending excluding adult co-offending are as follows: rape, 1.65; robbery, ns; aggravated assault, 0.91; simple assault, 1.74; total violence, 1.29.
By gender. The adjustment ratios for male juvenile offending including adult co-offending are as follows: rape, 3.05; robbery, ns; aggravated assault, ns; simple assault, 1.42; total violence, 1.41. The adjustment ratios for male juvenile offending excluding adult co-offending are as follows: rape, ns; robbery, ns; aggravated assault, ns; simple assault, 1.69; total violence, 1.68. The adjustment ratios for female juvenile offending including adult co-offending are as follows: rape, ns; robbery, ns; aggravated assault, ns; simple assault, 1.42; total violence, 1.41. The adjustment ratios for female juvenile offending excluding adult co-offending are as follows: rape, ns; robbery, ns; aggravated assault, ns; simple assault, 1.69; total violence, 1.68 .

By race. The adjustment ratios for white juvenile offending including adult co-offending are as follows: rape, ns; robbery, ns; aggravated assault, 1.48; simple assault, 1.79; total violence, 1.59. The adjustment ratios for white juvenile offending excluding adult co-offending are as follows: rape, ns; robbery, ns; aggravated assault, 1.90; simple assault, 1.68; total violence, 1.53. The adjustment ratios for black juvenile offending including adult co-offending are as follows: rape, ns; robbery, ns; aggravated assault, 0.63; simple assault, 1.99; total violence, 1.11. The adjustment ratios for black juvenile offending excluding adult co-offending are as follows: rape, ns; robbery, ns; aggravated assault, 0.59; simple assault, 2.06; total violence, 1.53. The adjustment ratios for other-race juvenile offending including adult co-offending are as follows: rape, ns; robbery, ns; aggravated assault, 2.29; simple assault, 3.75; total violence, 2.26. The adjustment ratios for other-race juvenile offending excluding adult co-offending are as follows: rape, ns; robbery, ns; aggravated assault, 1.0; simple assault, 3.55; total violence, 3.18 .

Although this adjustment procedure is useful, it must be used with caution. The 18-month overlap period does not provide many data for estimating adjustment ratios. The NCVS sample was not expanded during this period. Half the usual NCVS sample completed the pre-1992 instrument and half the post-1992 instrument. As a result, the reliability of the estimates from the overlap period is less than that of the NCVS generally. This means that the adjustment ratios are likely to be unstable for smaller population subgroups and rare offenses. Moreover, the accuracy of the adjustment ratios is likely to decrease the farther back in time one goes from the overlap period. For these reasons, this Bulletin presents trends only back to 1980, and these trends are limited to large classes of violent crime and major population groups. More detailed trends were produced for the post-1992 period (see "Trends in Offending Rates Since 1993" on pages 8-11), when a consistent design was used for the full NCVS sample.
The trends in serious violent offending for juveniles are broadly similar in the two data sources. Both show decreases in serious violent offending until about 1986-87 and increases thereafter until around 1994, when sharp decreases began and continued until 1998. Both race and gender disproportionality declined between 1980 and 1998 in both the UCR and NCVS data, as the overrepresentation of male offenders and the overrepresentation of black offenders decreased.

This examination of offending using NCVS data confirms the general picture of offending derived from UCR arrest data. At the same time, the greater racial disproportionality and the lower gender disproportionality found in the arrest data raise some questions. It is tempting to infer that police policy is the likely cause of these differences, specifically, that the police tend to arrest black offenders more often than white offenders or female offenders more often than male offenders. However, recent research (Pope and Snyder, in press) finds no support for these contentions, at least as they apply to serious violent crimes. 
Other explanations must be considered. One factor may be differential reporting of crimes by victims. For example, if victims of crime by black offenders are more likely to report their victimization to the police, then the arrest rate for black offenders will be higher even if the police treat every case about equally. Other factors may be differences in the scope, definitions, and procedures used in police record systems and victim surveys. The UCR arrest rates, for example, include arrests for events that are not asked about in the NCVS, such as commercial robbery, which in the UCR arrest data is not separated from noncommercial robbery and thus cannot be removed from the dataset to allow equal comparison with the NCVS data. If these events involve black offenders more than white offenders, then this could account for the greater racial disproportionality in the arrest data relative to the offending data. Similarly, the fact that larger urban places (which have disproportionately large black populations) report more reliably than smaller places in the UCR may lead to the overrepresentation of black juveniles in the UCR arrest data. If analysts adjusted the UCR arrest data to take the missing information into account more systematically, the differences between the police and victim survey data in race and gender disproportionality might disappear.

All of these explanations-and othersmust be pursued to understand the apparently discrepant pictures of offenders emerging from the UCR and the NCVS. The good news is that most of these alternative explanations for the observed differences can be examined with the UCR and NCVS data. Although beyond the scope of this analysis, it is possible, for example, to develop and apply adjustments in the UCR to account for the overrepresentation of large population places. Then this explanation for black overrepresentation in the UCR data would be eliminated.

Finally, this examination of victim data offers a view of co-offending that is not often obtained (or obtainable) from police data. The majority of juvenile violent offending is done in groups. About one-third of this group offending involves adults. Male juveniles are more disposed to group offending than female juveniles, and black juveniles much more than white juveniles. The declines in the juvenile offending rates for serious violent crimes between 1994 and 1998 were greatest for juvenile co-offending, especially for blacks. It is unclear why the drop in juvenile co-offending was so steep for blacks compared with whites. ${ }^{9}$ Possible explanations for this dramatic decrease in violent co-offending among black juveniles should be explored empirically to enhance the understanding of the recent drop in overall crime, with particular attention to the disparate declines in lone and group offending.

\section{Endnotes}

1. The numerator for the arrest rates presented in this Bulletin is arrested juveniles between the ages of 10 and 17. The denominator for the arrest rates is all juveniles between ages 12 and 17 . This denominator was used to be consistent with the denominator for the offending rates from the NCVS. Because there are relatively few arrested persons younger than 12 in the UCR data, including them in the numerator (but not the denominator) of the rate will not distort the arrest rate by much. The UCR arrest rates used in this Bulletin will be slightly higher than they should be.

2. For ease of reading and to maintain consistency within the Bulletin, rounded numbers are used in calculations and presented in the text. The methodology used to calculate the trends presented in the Bulletin is described in "Computing Offending Rates With the NCVS" (see pages 4-5). See also "Adjusting NCVS Data" (page 16).

3. The Survey of Inmates in State and Federal Facilities includes information on the crime event that brought the inmate to prison, but the respondents are largely adults.

4. The imprecision of this statement comes, in part, from the difficulty of judging the age of offenders in the course of a criminal event and the fact that most adult co-offenders are young adults. Victims may overestimate or underestimate the age of some people in the group of offenders. In some cases, they may perceive adults to be juveniles; in others, they may perceive juveniles to be adults. There is no reason, however, to believe that these errors in identifying the age of offenders will be in one direction. Indeed, it seems more likely that these errors will be in both directions and will therefore be offsetting to some degree. This would mean that any ambiguity in distinguishing "juvenile offending" comes largely from the prevalence of co-offending or group offending (specifically group offending that involves both juveniles and young adults), not from victims' misidentification of offenders' age.

5. All comparisons of statistics made in this report are statistically significant at the 0.1 level or less. The standard errors used in these statistical tests take into account the complex sampling used in the NCVS.

6. This pattern is broadly consistent with the theories of Blumstein and Wallman (2000) concerning the increase in violence in cities during the late 1980s and early 1990s. They contend that the increases in violence were due initially to the drug trade. Teenagers were recruited to participate in drug distribution, presumably with adults. This would increase adult co-offending. Participation in drug distribution required weapons, and the widespread carrying of weapons encouraged even those not in the drug trade to arm themselves. The availability of arms among teenagers led to increases in serious violence among teenagers not involved in drug distribution. This could explain increases in juvenile-only offending after the initial increases in adult co-offending with juveniles.

7. The other serious violent crime category (forcible rape) is relatively rare (1.12 per 1,000), and trends are unstable.

8 . The percentages for adult co-offending were calculated from peaks in 1994.

9. As Blumstein and Wallman (2000) argue, the routinization of the drug trade and the decrease in violence attendant to the drug trade may account for this. If juveniles were recruited into the drug trade, it is not unreasonable to assume that they participated in groups (even gangs) distributing drugs. In addition, it is reasonable to assume that they would also participate in the violence attendant to the drug trade in groups. As the drug trade became more organized and less violent, the need for group violence diminished. Even if these juveniles did not participate in the drug trade, living in areas with high levels of violence virtually requires affiliation with a group for protection. This, in turn, increases the chance of co-offending.

\section{References}

Biderman, A.D., and Lynch, J.P. 1991. Understanding Crime Incidence Statistics: Why the UCR Diverges From the NCS. New York, NY: Springer Verlag.

Blumstein, A., and Wallman, J. 2000. The Crime Drop in America. New York, NY: Cambridge University. 
Dodge, R. 1987. Series Crime: Report of a Field Test. Technical Report. Washington, DC: U.S. Department of Justice, Office of Justice Programs, Bureau of Justice Statistics.

Federal Bureau of Investigation. 1999. Crime in the United States, 1998. Washington, DC: U.S. Department of Justice.

Jarvis, J.P., and Lynch, J.P. 1996. Towards an error profile of the Uniform Crime Reports: Assessing the effects of imputation. Unpublished paper presented at The Workshop on the Quantitative Analysis of Crime and Justice Data, Inter-university Consortium for Political and Social Research, University of Michigan, August 2, 1996.

Kindermann, C., Lynch, J.P., and Cantor, D. 1997. The Effects of the Redesign on Victimization Estimates. Data Brief. Washington, DC: U.S. Department of Justice, Office of Justice Programs, Bureau of Justice Statistics.

Lynch, J.P., Berbaum, M., and Planty, M. 1999. Investigating Repeat Victimization With the National Crime Victimization Survey. Report to the National Institute of Justice.

Lynch, J.P., and Cantor, D. 1996. Models for adjusting the NCS trend to account for design differences between the NCS and the NCVS. Memorandum to the American Statistical Association Committee on Law and Justice Statistics, May 28, 1996.

Maltz, M. 1999. Bridging the Gap in Police Crime Data. Washington, DC: U.S. Department of Justice, Office of Justice Programs, Bureau of Justice Statistics.

Planty, M.G. 2000. Examining the differential returns from robbery incidents. Unpublished dissertation. Washington, DC:
American University, School of Public Affairs.

Pope, C., and Snyder, H. In press. Race as a Factor in Juvenile Arrests. Bulletin. Washington, DC: U.S. Department of Justice, Office of Justice Programs, Office of Juvenile Justice and Delinquency Prevention.

Rand, M., Lynch, J.P., and Cantor, D. 1997. Long Term Trends in Crime Victimization. Washington, DC: U.S. Department of Justice, Office of Justice Programs, Bureau of Justice Statistics.

\section{Rennison, C. 2000. Criminal Victimization} in the United States, 1999. Washington, DC: U.S. Department of Justice, Office of Justice Programs, Bureau of Justice Statistics.

Singer, S. 1981. Homogeneous victimoffender populations: A review and some research implications. Journal of Criminal Law and Criminology 72(2):779-788.

\section{Related Online OJJDP Publications}

If you are interested in more information about juvenile violence and victimization, please consult the recently completed OJJDP publications listed below. These publications are available in Adobe Acrobat and HTML online formats and can be downloaded from OJJDP's Web site (ojjdp.ncjrs.org). Click on "Publications" to access an alphabetical list of titles or to browse documents by topic area. You may also order copies of these and other publications by calling the Juvenile Justice Clearinghouse at 800-638-8736.

Addressing Youth Victimization (NCJ 186667). This Action Plan Bulletin explains that although violent crime has decreased significantly since publication of Combating Violence and Delinquency: The National Juvenile Justice Action Plan in 1996, too many children continue to be victims of violent crime, child abuse and neglect, and exposure to violence. In turn, this victimization perpetuates a cycle of violence in which children later become the perpetrators of violence against others. This Bulletin describes a variety of programs and services that have been implemented at the State and local levels to address youth victimization and its effects. Federal agencies are collaborating to support this work through efforts such as the Coordinating Council's call to break the cycle of violence. Available at ojjdp.ncjrs.org/ pubs/violvict.html\#186667.

Animal Abuse and Youth Violence (NCJ 188677). This OJJDP Bulletin describes psychiatric, psychological, and criminal research linking animal abuse to interpersonal violence perpetrated by juveniles and adults. Particular attention is focused on the prevalence of cruelty to animals by children and adolescents and to the role of animal abuse as a possible symptom of conduct disorder. In addition, the motivations and etiology underlying the maltreatment of animals are thoroughly reviewed. The Bulletin includes recommendations to curb such cruelty, while providing contact information for additional resources concerned with violence perpetrated against animals and people. Available at ojjdp.ncjrs.org/pubs/violvict.htm/\#188677.

\section{Gun Use by Male Juveniles: Research and Prevention} (NCJ 188992). This OJJDP Bulletin examines patterns of gun ownership and gun carrying among adolescents, drawing on data from OJJDP's Rochester Youth Development Study. The Bulletin, which is part of the Youth Development Series, also addresses the interrelationship between gangs and guns and describes prevention programs, including the Boston Gun Initiative, the Office of Community Oriented Policing Services Youth Firearms Violence Initiative, and OJJDP's Partnerships To Reduce Juvenile Gun Violence Program. Effective efforts to reduce illegal gun carrying and gun violence among youth require the support and participation of multiple community agencies. The information presented in this Bulletin is intended to enhance those efforts. Available at ojjdp.ncjrs.org/ pubs/violvict.htmI\#188992.

\section{Juvenile Delinquency and Serious Injury Victimization} (NCJ 188676). This OJJDP Bulletin draws on data from two OJJDP longitudinal studies on the causes and correlates of juvenile delinquency-the Denver Youth Survey and the Pittsburgh Youth Study-to explore the interrelationship between delinquency and victimization. The Bulletin, part of OJJDP's Youth Development Series, focuses on victims of violence who sustained serious injuries as a result of the victimization. Being victimized may lead to victimizing others. The studies found that many victims were prone to engage in illegal activities, associate with delinquent peers, victimize other delinquents, and avoid legal recourse in resolving conflicts. A clearer understanding of the patterns and predictors of victimization offers the potential for increased effectiveness in designing and implementing strategies to reduce both victimization and offending. Available at ojjdp.ncjrs.org/pubs/ violvict.html\#188676. 
Snyder, H. 2000. Juvenile Arrests 1999. Washington, DC: U.S. Department of Justice, Office of Justice Programs, Office of Juvenile Justice and Delinquency Prevention.

Snyder, H., and Sickmund, M. 1999. Juvenile Offenders and Victims: 1999 National Report. Washington, DC: U.S. Department of Justice, Office of Justice Programs, Office of Juvenile Justice and Delinquency Prevention.

Thornberry, T., and Krohn, M. 2000. The self-report method for measuring delinquency and crime. In Criminal Justice 2000: Measurement and Analysis of Crime and Justice, vol. 4, edited by D. Duffee, D. McDowall, B. Ostrom, R. Crutchfield, S. Mastrofski, and L. Mazerolle. Washington, DC: U.S. Department of Justice, Office of Justice Programs, National Institute of Justice.

This paper was prepared with funds provided to the National Center for Juvenile Justice by the Office of Juvenile Justice and Delinquency Prevention to support its National Juvenile Justice Data Analysis Project (1999-JN-FX-K002).

Points of view or opinions expressed in this document are those of the author and do not necessarily represent the official position or policies of OJJDP or the U.S. Department of Justice.

The Office of Juvenile Justice and Delinquency Prevention is a component of the Office of Justice Programs, which also includes the Bureau of Justice Assistance, the Bureau of Justice Statistics, the National Institute of Justice, and the Office for Victims of Crime.

\section{Acknowledgment}

James $\mathrm{P}$. Lynch is a Professor in the Department of Justice, Law, and Society at American University.

\section{Share With Your Colleagues}

Unless otherwise noted, OJJDP publications are not copyright protected. We encourage you to reproduce this document, share it with your colleagues, and reprint it in your newsletter or journal. However, if you reprint, please cite OJJDP and the authors of this Bulletin. We are also interested in your feedback, such as how you received a copy, how you intend to use the information, and how OJJDP materials meet your individual or agency needs. Please direct your comments and questions to:

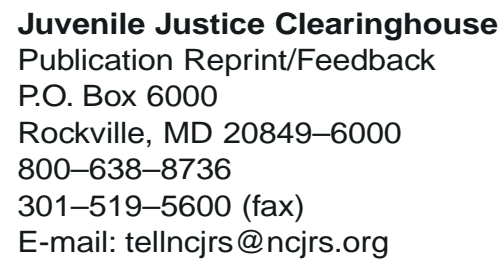

\section{Take the Online Pujis jo} OJJDP Information
It's Fast

It's Easy

It's Free ant to know more about the issues in this Bulletin or related information?

Log on to oijdp.ncirs.org:

Browse titles alphabetically or by topic.

Discover the latest OJJDP releases.

Subscribe to OJJDP's listserv JUVJUST and the electronic newsletter JUSTINFO.

> Link to the NCJRS Abstracts Database to search for publications of interest. 
U.S. Department of Justice

Office of Justice Programs

Office of Juvenile Justice and Delinquency Prevention
PRESORTED STANDARD POSTAGE \& FEES PAID DOJ/OJJDP PERMIT NO. G-91

Washington, DC 20531

Official Business

Penalty for Private Use $\$ 300$ 